\title{
Perspective
}

PERSPECTIVE Actualité en histoire de l'art

2| 2007

La Grande-Bretagne/Période moderne

\section{Une scintillante pénombre : vingt-cinq ans de recherches sur les grottes artificielles en Europe à la Renaissance}

Sparkles in the Shade: Twenty-five years of research on artificial grottoes in

Renaissance Europe

Glitzernder Halbschatten: Fünfundzwanzig Jahre Forschung über die

künstlichen Grotten der Renaissance in Europa

Una penombra scintillante: venticinque anni di ricerche sulle grotte artificiali

del Rinascimento in Europa

Una brillante penumbra: veinticinco años de investigaciones sobre las grutas

artificiales en la Europa del Renacimiento

\section{Hervé Brunon}

\section{OpenEdition}

Journals

Édition électronique

URL : http://journals.openedition.org/perspective/3829

DOI : $10.4000 /$ perspective.3829

ISSN : 2269-7721

Éditeur

Institut national d'histoire de l'art

Édition imprimée

Date de publication : 30 juin 2007

Pagination : 341-376

ISSN : $1777-7852$

Référence électronique

Hervé Brunon, « Une scintillante pénombre : vingt-cinq ans de recherches sur les grottes artificielles en Europe à la Renaissance », Perspective [En ligne], 2 | 2007, mis en ligne le 31 mars 2018, consulté le 10 décembre 2020. URL : http://journals.openedition.org/perspective/3829 ; DOI : https://doi.org/ 10.4000/perspective.3829 


\title{
Une scintillante pénombre : vingt- cinq ans de recherches sur les grottes artificielles en Europe à la Renaissance
}

\author{
Sparkles in the Shade: Twenty-five years of research on artificial grottoes in \\ Renaissance Europe \\ Glitzernder Halbschatten: Fünfundzwanzig Jahre Forschung über die \\ künstlichen Grotten der Renaissance in Europa \\ Una penombra scintillante: venticinque anni di ricerche sulle grotte artificiali \\ del Rinascimento in Europa \\ Una brillante penumbra: veinticinco años de investigaciones sobre las grutas \\ artificiales en la Europa del Renacimiento
}

\section{Hervé Brunon}

Pour Luigi Zangheri

Je tiens à remercier Flaminia Bardati, Françoise Boudon, Philippe Morel, Monique Mosser et Aurélia Rostaing pour leur aide dans la préparation de cette chronique bibliographique.

1 «Les Grotes sont faites pour representer les Antres sauvages, soit qu'elles soient taillées dans les rochers naturels, ou basties expressément autre part : aussi sont-elles ordinairement tenuës sombres, et aucunement obscures ". C'est par cette définition que s'ouvre le chapitre du Traité du jardinage selon les raisons de la nature et de l'art de Jacques Boyceau de la Barauderie consacré aux grottes. Précisant que les grottes artificielles peuvent être ornées "d'ouvrages rustiques », de " pierres spongieuses », de "petrifications estranges, et de diverses sortes de coquillages», de jeux d'eau, d'automates hydrauliques, de sculptures et de peintures - appartenant ainsi au registre des Gesamtkunstwerke avant la lettre -, Boyceau condensait près d'un siècle de 
pratique en France et cent cinquante ans de théorie en Europe, depuis les allusions d'Alberti sur les grottes des Anciens (BOyCEAU, 1638, p. 80 ; ALBERTI, [1485] 2004, p. 435).

2 Le développement des grottes artificielles constitue en effet l'un des aspects artistiques les plus significatifs du mouvement de renovatio antiquitatis lancé par la Renaissance. Ce type d'espaces architecturaux était apparu avec l'hellénisme et s'était affirmé dans l'art des jardins romains, désigné par différents vocables comme amaltheum (Cicéron), musaeum (Pline l'Ancien) ou encore nymphaeum ${ }^{1}$. Les équivalents modernes des modèles antiques présentent de même une certaine fluctuation terminologique, qui subsiste encore aujourd'hui entre les mots "grotte» et "nymphée ». Le vocabulaire typologique et technique du jardin, compilé par Marie-Hélène Bénetière pour la collection de l'Inventaire général grâce à un travail systématique sur les traités, appelle d'une part "grotte de jardin" une "fabrique [petite construction de jardin] dont l'espace intérieur est orné de céramique, de pétrifications, de congélations ou de stalactites, auxquels sont généralement associés des jeux d'eau (salle de fraîcheur) ", d'autre part «nymphée de jardin » une "construction élevée au-dessus d'une source naturelle ou artificielle, généralement en forme de grotte, accueillant un bassin d'ornement, une fontaine, des jeux d'eau, etc. » (BÉNETIÈRE, 2000, p. 178 et p. 138). Une distinction, au demeurant souple, est ainsi suggérée selon que l'accent est mis sur le décor minéral ou la présence de l'eau. Les documents anciens sont souvent ambigus de ce point de vue. En italien par exemple, les recherches lexicographiques d'Elena Cenci ont montré que le terme ninfeo n'est vraiment utilisé au sens de grotte artificielle qu'à partir de la seconde moitié du XVIII ${ }^{\mathrm{e}}$ siècle et n'apparaît pratiquement pas chez les auteurs toscans antérieurs, qui préfèrent utiliser grotta ou fontana, voire stanza (CENCI, 1992)2. Ce dernier mot renvoie d'ailleurs à l'existence de grottes "domestiques", entièrement intégrées à la demeure sans lien direct avec le jardin, dont on rencontre notamment de nombreux exemples à Florence aux XVI ${ }^{\mathrm{e}}$ et XVII ${ }^{\mathrm{e}}$ siècle (PERONI, 1992a et 1992b ; RINALDI, 1987s, 1987b et 2001a). Une telle variété terminologique reflète, sans la recouvrir exactement, la richesse typologique.

\section{Les développements de l'historiographie jusqu'en 1982}

3 Cette diversité avait déjà attiré l'attention d'Ernst Kris dans l'article fondateur qu'il publia en 1926, "Le style rustique", issu de sa thèse et accessible depuis peu en français dans une édition annotée par Patricia Falguières ${ }^{3}$. Enquêtant sur l'histoire d'une "pratique technique ", le moulage d'après nature, et s'interrogeant sur la place du naturalisme dans l'art maniériste, l'élève de Schlosser s'était penché sur ces décors complexes où il relevait notamment, à partir du témoignage de Vasari sur les deux fontaines aménagées par Giovanni da Udine à la villa Madame de Rome (vers 1520-1525), « deux conceptions différentes dans des monuments de la même époque. La grotte des éléphants, grotte artificielle aux proportions claires, s'appuie sur l'Antiquité » en imitant le décor d'un temple de Neptune découvert récemment. L'autre grotte est entourée d'un bosco (parcelle boisée) « et ses formes décoratives s'inspirent de la nature » (KRIS, [1926] 2005, p. 151-152). Parmi les essais précurseurs, il faut aussi compter la thèse de Bertha Harnes Wiles, publiée en 1933, sur les fontaines des sculpteurs florentins, rassemblant un important matériel d'archives et proposant un classement par types et une analyse stylistique des principales réalisations (WILES, 1933). 
Ce n'est qu'au début des années 1960 que les grottes artificielles suscitèrent un nouvel intérêt, notamment de la part de personnalités soucieuses, comme auparavant Kris, de rendre compte d'objets que l'histoire de l'art traditionnelle laissait encore en marge, tels les jardins et les illustrations scientifiques: Eugenio Battisti, dans sa grande enquête sur «l'anti-Renaissance " (BATTISTI, [1962] 2005; voir aussi BATTISTI, [1972] 2004), et Detlef Heikamp, à travers une série d'études sur les grottes de Boboli et de Pratolino à Florence (HEIKAMP, 1964, 1965, 1969a, 1969b et 1978). Dès lors, la plupart des synthèses sur le maniérisme incluront des pages touchant spécifiquement aux grottes artificielles en tant que manifestations emblématiques de cette culture artistique (par exemple SHEARMAN, [1967] 1990, p. 125-133 ; CHASTEL, [1968-1969] 1989, p. 324-328; PINELLI, [1993] 1996, p. 248-262 ; FALGUIÈRES, 2004a, p. 102-104).

5 La recherche sur ce domaine s'est ultérieurement institutionnalisée, du moins aux États-Unis et en Italie, à la faveur du développement d'une approche scientifique de l'histoire des jardins. En 1977, Elisabeth Blair MacDougall, directrice des études sur l'architecture du paysage au Centre de recherche de Dumbarton Oaks à Washington (Harvard University), choisit, pour le cinquième colloque sur l'histoire de l'architecture du paysage, et après des éditions centrées sur une aire culturelle - Italie, Angleterre, France et Islam -, un sujet thématique, les fontaines de jardins à la Renaissance (MACDOUGALL, 1978a), où intervint notamment Naomi Miller sur les grottes françaises (MILLER, 1978) et à l'occasion duquel une petite exposition présentait une trentaine de gravures tirées de livres de la bibliothèque fondée par Mrs. Robert Woods Bliss, le fonds initial de la Garden Library de Dumbarton Oaks (Fons Sapientiæ, 1977). Frank Joseph Alvarez soutint en 1981, à Columbia University, sa thèse sur les nymphées de la Renaissance dans la région de Rome (ALVAREZ, 1981). En Italie, Marcello Fagiolo réunit un groupe de travail auprès de l'Istituto di Storia dell'Architettura de l'Université de Florence sur les problématiques inhérentes à la dialectique entre architecture et nature dans le cadre culturel de la Renaissance. Deux importants volumes furent issus de cette entreprise collective. Le premier, Natura e artificio, envisageait l'ordre rustique, les fontaines et les automates à l'échelle du maniérisme européen (faGiolo, 1979); il comportait notamment des contributions générales sur la grotte comme représentation de la nature en lien avec les préoccupations scientifiques (ACIDINI LUCHINAT, 1979) et en tant que laboratoire d'une osmose entre art et nature (RINALDI, 1979), ainsi qu'une anthologie de sources théoriques et descriptives en rapport (ACIDINI LUCHINAT, RINALDI, 1979). Le second, La città effimera e l'universo artificiale del giardino, concernait spécifiquement la Toscane, s'inscrivant dans la riche série de publications qui accompagnèrent les mémorables expositions de Florence en 1980 sur les Médicis et l'Europe du XVI ${ }^{\mathrm{e}}$ siècle (FAGIOLO, 1980).

6 La multiplication des travaux invitait à une première tentative de synthèse, à laquelle s'attacha Naomi Miller dans un livre paru en 1982, où elle envisageait les grottes de jardin depuis l'Antiquité jusqu'au monde contemporain dans leurs fondements classiques et à travers l'évolution de leurs formes et de leurs significations en fonction $\mathrm{du}$ contexte culturel, notamment l'attitude envers la nature. Le chapitre sur la Renaissance abordait essentiellement l'Italie et, plus rapidement, la France (MILLER, 1982, p. 35-58). Si le corpus des exemples mobilisés ne s'était pas considérablement étoffé par rapport à celui d'E. Kris, il était beaucoup mieux documenté.

7 La date de cette publication coïncide avec un tournant dans l'historiographie des jardins. La Charte de Florence (1981), élaborée par un comité international d'experts 
mis en place dix ans plus tôt sous l'égide de l'Icomos-Ifla (Conseil international des monuments et des sites-International Federation of Landscape Architects), définissait les principes de protection, conservation et restauration des jardins historiques en engageant à promouvoir leur connaissance (BAGATTI VALSECCHI, 1987). La fortune critique des grottes artificielles, structures particulièrement fragiles, a sans conteste bénéficié de ce regain d'intérêt, s'infléchissant également dans de nouvelles directions grâce à certaines démarches d'inventaire systématique et à la multiplication des chantiers de restauration. Pour évoquer les principaux travaux qui ont jalonné ces vingt-cinq années de recherches, le découpage géographique reste le plus commode. L'Italie, où les grottes sont attestées dès les années 1520 , a été abondamment étudiée, y compris pour les aspects techniques et les enjeux culturels. La France a été plus ponctuellement explorée pour les réalisations prestigieuses qui se multiplient dès 1550. Les approches touchant au développement des grottes dans le reste de l'Europe, à partir de la seconde moitié $\mathrm{du} \mathrm{xVI}^{\mathrm{e}}$ siècle, invitent aujourd'hui à dépasser l'idée traditionnelle d'une diffusion « centrifuge » de l'italianisme.

\section{Grottes italiennes : un patrimoine amplement exploré par des méthodes plurielles}

8 Les recherches sur les grottes italiennes ont été stimulées par la tenue de deux colloques. En 1985, Cristina Acidini Luchinat, Lauro Magnani et Mariachiara Pozzana organisèrent une journée d'études à Florence qui faisait le point sur les méthodes de connaissance et de conservation, principalement à partir d'exemples florentins et génois (ACIDINI LUCHINAT, MAGNANI, POZZANA, 1987). Parmi les seize contributions publiées dans les actes, certaines envisageaient ainsi la question des relevés architecturaux (CONFORTI, 1987a) ou de la documentation photographique (BIASION, 1987) ${ }^{4}$. La seconde manifestation eut plus d'ampleur: en 1998, le Comitato nazionale per lo studio e la conservazione dei giardini storici, organe consultatif du Ministero per i beni e le attività culturali ${ }^{5}$, consacra son cinquième congrès international à la culture des grottes et des nymphées en Italie et en Europe. Cette rencontre, qui attira la plupart des spécialistes de l'histoire des jardins de la péninsule et bon nombre d'experts étrangers, toucha à tous les niveaux d'analyse, qu'il s'agisse de panoramas régionaux et d'études monographiques, d'éclairages techniques et d'exemples de restauration, ou encore d'approches plus générales sur des problématiques culturelles (LAPI BALLERINI, MEDRI, 1999). Ces trois grandes rubriques permettent d'ailleurs de distribuer l'ensemble des travaux menés sur les grottes artificielles en Italie.

Le "convegnone» de 1998 fut de plus l'occasion de lancer un colossal travail d'inventaire des grottes et des nymphées à l'échelle nationale, piloté par le Comitato nazionale avec le concours de nombreuses institutions. Ce recensement a abouti à la publication d'un atlas en deux volumes, couvrant respectivement l'Italie du sud et du nord, avec pour chaque région un essai introductif puis une série de fiches historiques, descriptives et éventuellement interprétatives, classées par provinces (CAZZATO, FAGIOLO, GIUSTI, 2001 et 2002). Cet ensemble traite d'un patrimoine considérable toutes époques confondues, parmi lequel les grottes de la Renaissance toujours conservées figurent en bonne place. 


\section{La Toscane et les grottes médicéennes}

$10 \mathrm{Au}$ niveau régional, la Toscane fournit les cas les plus étudiés avec les réalisations médicéennes de la seconde moitié $\mathrm{du} \mathrm{xvI} \mathrm{x}^{\mathrm{e}}$ siècle, que l'article de Kris passait déjà en revue. Le plus célèbre à tous points de vue reste la Grande Grotte de Boboli à Florence, objet des articles déjà cités de Heikamp (неiкAмP, 1964, 1965 et 1978), sur laquelle l'historien de l'art est revenu récemment à l'occasion d'une exposition sur le palais Pitti (неiкAMP, 2003). C'est sous la direction de l'ingénieur et architecte Bernardo Buontalenti qu'un nymphée, préalablement construit par Giorgio Vasari, fut transformé entre 1583 et 1593, pour le compte du grand-duc François I ${ }^{\text {er }}$ de Médicis, en une grotte composée de trois salles en enfilade. Grâce aux recherches dans les archives, récemment encouragées par une longue campagne de restauration qui a permis de rouvrir la grotte au public en décembre 2003, l'équipe des artistes qui y travaillèrent - notamment les sculpteurs Piero di Tommaso Mati et Giovan Battista Ferrucci del Tadda ainsi que les peintres Bernardino Poccetti et Ludovico Cardi dit Cigoli - et la chronologie de l'exécution sont aujourd'hui assez bien connues, même si certains détails de datation fine restent discutés; la lumière a également été faite sur les modifications postérieures de la grotte, notamment dues à Gaetano Bianchi et Rinaldo Barbetti à la fin du XIX ${ }^{e}$ siècle (ZANGHERI, 1991a ; GALLETTI, 1999, 2001a et 2003 ; MEDRI, 1999 et 2003). Plus ouvert demeure le problème de la lecture de ce décor complexe, qui semble se partager entre des thématiques si différentes que les spécialistes ont longtemps douté de l'existence d'un projet iconographique cohérent au-delà de l'évocation de thèmes très génériques comme le contraste entre l'art et la nature (par exemple LAZZARO, 1990, p. 201-208) ; l'interprétation n'est pas facilitée par la divergence entre les sources sur l'identification du groupe sculpté de Vincenzo de' Rossi installé à l'entrée de la deuxième chambre (CASTELLI, 1991; GALLENI, 1991). Les hypothèses stimulantes qu'ont proposées Alessandro Rinaldi et Philippe Morel seront évoquées plus loin. Dans son ultime contribution, Detlef Heikamp suppose que deux statues antiques, aujourd'hui conservées aux Offices, furent ajoutées dans la troisième salle au cours des années 1590, sous Ferdinand $\mathrm{I}^{\text {er }}$ de Médicis, et suggère que l'ensemble constituait une sorte de musée de sculptures, dans une atmosphère célébrant les forces de la nature et les quatre éléments (HEIKAMP, 2003). J'ai pour ma part proposé de voir dans la succession des trois salles, qui aboutit à la chambre de Vénus centrée sur la figure de Giambologna, un parcours mettant en scène une initiation à l'amour, dans une perspective platonisante, selon un esprit très proche de l'Hypnerotomachia Poliphili ou Songe de Poliphile de Francesco Colonna (1499) et de son recours à l'alternance entre deux poétiques du paysage, amène ou effroyable, comme ressort narratif (BRUNON, 2004a).

11 Surnommée « grotticina » pour la différencier de la précédente, l'autre grotte de Boboli, dite de Madame, fut construite entre 1553 et 1555 sous la direction de Davide Fortini, très probablement sur une idée de son beau-père Niccolò Tribolo - artiste mieux connu depuis le colloque monographique de 2000 (PIERI, ZANGHERI, 2001) -, lequel avait défini un projet d'ensemble pour l'aménagement du nouveau jardin dès son achat en février 1550 par Éléonore de Tolède, épouse de Côme ${ }^{\mathrm{er}}$ de Médicis, avant de mourir prématurément en septembre de la même année. Les études récentes ont souligné l'intégration de cette grotte dans le programme initial du sculpteur pour le nouveau jardin, reconstitué à partir des archives (RINALDI, 1991). Le décor sculpté de la fontaine murale occupant l'abside du fond, exécuté principalement par Giovanni Fancelli, est 
dominé par une tête de bélier au sommet et une chèvre aux mamelles gonflées de lait à la base. Il rendrait ainsi hommage à Côme, qui avait comme signe zodiacal le capricorne et avait reçu la Toison d'Or en 1545, peut-être en faisant allusion à la grotte de Pan décrite dans l'Arcadie de Sannazar - où un autel est surmonté de l'effigie du dieu (PETRUCCI, 2001) - ou en se référant à l'Amaltheum d'Atticus mentionné par Cicéron, dont la grotticina aurait été conçue comme la reformulation moderne (RINALDI, 2001b).

Beaucoup de questions subsistent à propos de la grotte dite des Animaux dans la villa de Castello, ainsi baptisée en raison des figures zoologiques ornant ses trois niches. Le défaut d'archives suffisamment explicites ne permet pas d'établir avec précision la chronologie du chantier ni la paternité des différents éléments (GALLETTI, 2001b). On présume que la grotte creusée au centre du mur de soutènement de la première terrasse, élément nodal dans la distribution du réseau hydrique, fut prévue dès le projet initial du jardin confié à Tribolo en 1538 (LAPI BALLERINI, 1999). La décoration intérieure ne semble en revanche se mettre en place qu'à partir de 1565, sous la direction de Fortini, pour se poursuivre au moins jusqu'en 1579. Vasari évoque en 1568 les sculptures animalières auxquelles travaillait alors Antonio di Gino Lorenzi, que l'on identifie généralement comme destinées à cette grotte, bien qu'une telle attribution ne soit pas sans poser problème. Certains des oiseaux de bronze qui complétaient la faune sculptée sont aujourd'hui au Bargello, attribués à Giambologna et Bartolomeo Ammannati (неIкAMP, 2006). L'éventuelle signification de l'ensemble demeure discutée depuis la contribution de Liliane Châtelet-Lange, qui privilégiait la figure centrale de la licorne et interprétait la grotte comme une évocation du paradis terrestre (CHÂTELETLANGE, 1968). La plupart des hypothèses plus récentes supposent qu'un chaînon central ne nous est pas parvenu : une ou plusieurs figures humaines (statues ou automates) qui auraient parachevé le dispositif iconographique. Des témoignages postérieurs (Agostino Del Riccio vers 1595, Joseph Furttenbach en 1627) suggèrent la présence d'un Orphée, qui viendrait ici participer à l'apologie de Côme orchestrée dans le reste du jardin (CONFORTI, 1987b). Une éventuelle représentation d'Adam aurait également pu renvoyer à l'épisode de la Genèse où le premier humain donne leurs noms aux animaux (ACIDINI LUCHINAT, 1992). Que la grotte ait pu illustrer un sujet précis, en rapport avec un texte mythologique ou biblique, reste donc une question ouverte. Claudia Lazzaro a en tout cas démontré que la plupart des animaux figurés devaient apparaître aux yeux des contemporains comme des «signes culturels » chargés d'associations emblématiques, héraldiques ou plus généralement symboliques, notamment en rapport avec la gloire des Médicis, telle la girafe, dont les Florentins gardaient le souvenir de l'exemplaire jadis donné par le Sultan d'Égypte à Laurent le Magnifique (LAzZARO, 1995).

13 Il est impossible de rendre compte ici de tous les travaux menés depuis 1982 sur les grottes de Pratolino, le fameux jardin aménagé par Buontalenti pour le grand-duc François entre 1569 et 1586, tant la bibliographie s'est accumulée depuis le rachat du parc à cette date par la province de Florence (notamment ZANGHERI, [1979] 1987; Il giardino d'Europa, 1986; VEZzosI, 1985, 1986 et 1990; Risveglio di un colosso, 1988). Le colosse de l'Apennin conçu par Giambologna a en particulier bénéficié d'études techniques fertiles, sur lesquelles nous reviendrons. Des très nombreuses grottes que renfermait le barco, deux seulement nous sont parvenues : la grotte de Cupidon (RINALDI, 2001c) et la petite grotte de l'Apennin, cette dernière ayant été notablement transformée depuis la fin du $\mathrm{XVII}^{\mathrm{e}}$ siècle (POZZANA, 2001). La très abondante 
documentation permet néanmoins de reconstituer la plupart des autres grottes aménagées à la fin du XVI ${ }^{\mathrm{e}}$ siècle (BRUNON, 2001a).

En dehors de ces prestigieuses réalisations médicéennes, l'attention s'est notamment portée sur le nymphée construit en 1573 par Bernardo Vecchietti, collectionneur et mécène, à proximité de sa villa dite «Il Riposo » à Bagno a Ripoli, au sud de Florence, qui se trouve longuement évoquée dans le dialogue homonyme sur les arts publié par Raffaello Borghini en 1584 (HЕIKAMP, 1981a). Représentant la fée Morgane, la sculpture de Giambologna qui ornait la grotte entièrement peinte, sans doute conçue par l'artiste lui-même et munie d'une façade rustique au bossage expressif, a en effet été redécouverte sur le marché antiquaire en 1989 (BURY, 1990; HEIKAMP, 1997) et l'ensemble a fait l'objet d'une restauration à la fin des années 1990 (colomo, 1997, 1999 et 2001). Il faut noter que le monument, qui comportait également à l'extérieur une fontaine, un lavoir et un abreuvoir (CARRARA, 2006), devait se trouver dans une partie publique de la propriété.

15 Toujours en Toscane, la région de l'ancienne république de Lucques comprend des cas intéressants mais moins copieusement étudiés. Récemment restauré, le nymphée de la villa Buonvisi-Bottini à Lucques doit dater des années 1580 et pourrait avoir été conçu par Ammannati ; entre la façade en arc de triomphe à ordre rustique, surmontée de deux dieux fleuves flanquant l'attique, et le mur de fond décoré de rocailles, devait se trouver l'espace intérieur de la grotte aujourd'hui privé de couverture (GIUSTI, 1999 et 2001). Datant de la fin du Xvi siècle, le nymphée de Pan de la villa del Vescovo à Marlia, propriété aujourd'hui englobée dans la villa Marlia-Pecci Blunt, présente une solution architecturale assez proche - une façade en arc de triomphe s'ouvrant sur un atrium puis une grotte couverte d'une coupole -, mais modifiée par l'ajout d'un second niveau au-dessus de la première pièce au début du Xx ${ }^{e}$ siècle (PETRUZZI, 2001).

Pour Sienne, il faut surtout signaler la villa Chigi alle Volte Alte, aménagée par Baldassare Peruzzi en 1502-1505 pour le compte de Sigismondo Chigi. Entièrement réalisé en briques, le nymphée est composé d'une grande exèdre semi-circulaire qui sert de fond à un bassin rectangulaire et s'ouvre par cinq arcades sur autant d'espaces intérieurs creusés en profondeur, dont le principal au centre, la grotte proprement dite, est recouvert de concrétions et contenait une statue de Neptune (ROTUNDO, 1998 et 2001). Certainement dérivée de modèles antiques romains, en particulier néroniens, cette construction monumentale précède de quelques années la villa Farnésine à Rome (1509-1511), conçue par Peruzzi pour le frère de Sigismondo, Agostino Chigi, et qui comprenait également une grotte surmontée d'une loggia servant de salle de banquet, décrite par Egidio Gallo en 1511 et sans doute rapidement détruite par les inondations du Tibre (CoFfin, 1979, p. 97).

\section{Fontaines, nymphées et grottes du Latium}

17 La région de la capitale pontificale présente un important corpus, où les frontières typologiques entre fontaines murales, nymphées et grottes proprement dites ne sont pas faciles à tracer (MACDOUGALL, 1978c ; FAGIOLO, MADONNA, 1990 ; COFFIN, 1991, p. 28-57).

Depuis l'étude que lui avait consacrée Christoph Luitpold Frommel (Frommel, [1969] 2003), le nymphée Colonna de Genazzano a suscité une vive discussion quant à son attribution à Bramante et sa datation (BURECA, 2001). Relevant de l'archéologie du bâti 
et de l'analyse constructive, les recherches conduites par Marina Döring ont totalement renouvelé la connaissance du monument à partir d'un relevé complet et d'études scientifiques de son état matériel menées en 1997-1998. Trois phases distinctes de réalisation sont ainsi mises en évidence. Par sa technique de construction et son système de mesures caractéristiques, le corps de bâtiment octogonal comprenant un bassin circulaire creusé dans le pavement se révèle appartenir à l'époque antique, où il servait peut-être de lieu de culte. La loggia à trois arcades et l'espace contigu, creusé d'une abside centrale, correspondent à l'intervention que Bramante dut réaliser, vers 1508-1514, pour le compte de Pompeo Colonna. L'ensemble fut restructuré et amplifié entre 1530 et 1559, probablement par l'architecte Giovanni Mangone pour Ascanio Colonna. En outre, l'auteur établit que dès la deuxième phase, l'édifice fut conçu comme une ruine artificielle à ciel ouvert, ayant vraisemblablement la fonction de théâtre d'eau (mais sans doute pas de thermes), qui s'insérait dans la vallée du Fossato, réaménagée par des terrassements et la mise en place de deux ou même trois lacs artificiels pour constituer un parc paysager orné de différents bâtiments, que l'on peut mettre en relation avec l'imaginaire de l'Hypnerotomachia Poliphili (DöRING, 2001).

Déjà évoqué par E. Kris, le cas de la villa Madame a surtout été débattu pour les projets architecturaux de tout le complexe et son chantier, notamment documentés par une série de plans (Andrea Palladio e la villa veneta..., 2005, cat.33, p. 239-246). Le décor hydraulique sera sans doute mieux compris grâce à la thèse en cours d'Yvonne Elet à New York University, qui a d'ores et déjà présenté une première analyse des conduites souterraines et des éléments disparus (ELET, 2005).

La fontaine construite à Rome par Giovanni Gaddi, sans doute dans sa vigna près du Colisée (COFFIN, 1991, p. 36-37), n'était jusqu'à présent connue que par la description très précise, détaillant le décor minéral de la grotte et la variété des jeux d'eau, qu'en donne Annibale Caro dans une lettre à Monsignor Guidiccioni de 1538, souvent citée et reproduite (MACDOUGALL, 1994, p. 84-85 ; AZZI VISENTINI, 1999, vol. I, p. 229-233). Caroline Elam a récemment mis en relation ce texte avec un dessin conservé à la Christ Church d'Oxford, parmi d'autres plans et vues de fontaines de villas appartenant à des membres de la Curie romaine au XVI e siècle (ELAM, 2005).

21 Articulé sur trois niveaux, le nymphée de la villa Giulia à Rome ne nous est parvenu qu'en grande partie dépouillé de son riche décor initial, documenté par une lettre d'Ammannati de 1555 (reproduite dans AZZI VISENTINI, 1999, vol. I, p. 263-273) et par de nombreux dessins, notamment des plans et élévations à la collection Cronstedt du Nationalmuseum de Stockholm et au Royal Institute of British Architects de Londres (TUTTLE et al., 2002, p. 163-195). Sa construction, où les rôles d'Ammannati, de Vasari et de Vignole ne sont pas unanimement départagés (FROMMEL, 2002), date de 1551-1552 et coïncide avec celle du bâtiment principal, mais les deux édifices ont dû naître comme unités séparées, comme le suggèrent les relevés, avant de se voir réunies par la cour et la loggia, postérieures selon les archives; l'ancien domaine comprend en outre une grotticina circulaire, non documentée, qui devait servir de glacière et à laquelle on accède par trois corridors parallèles dont celui du centre est peint de grotesques (BASILI, 2001).

L'histoire et l'iconographie de la fontaine de l'Orgue dans les jardins du Quirinal ont été étudiées à l'occasion de sa restauration (ANTELINI DONELLI, 1995); deux phases successives peuvent à présent être distinguées. Un premier état, dont la réalisation par Curzio Maccarone pour le cardinal Hippolyte d'Este vers 1565 impliqua sans doute Pirro 
Ligorio, était centré sur le thème du Parnasse avec des statues d'Apollon et des Muses et des scènes mythologiques sculptées en rapport avec l'eau, comme L'enlèvement d'Europe. Sous Clément VIII Aldobrandini, la grotte fut restructurée par Giovanni et Domenico Fontana, avec l'adduction de l'Acqua Felice et la mise en place d'un orgue hydraulique, tandis que le nouveau décor de mosaïques au niveau supérieur, exécuté par Pompeo Maderno et Giovangiacomo del Neri, dit Tivolino, déclinait cette fois les épisodes de la vie de Moïse. Exemple significatif du revival de la mosaïque médiévale sous la contre-réforme, cette transformation tendait à christianiser un cycle originellement mythologique célébrant la sacralité des eaux (FAGIOLO, 1998 et 2001).

Parmi les autres réalisations romaines, le nymphée de la Pluie des Orti Farnesiani sur le Palatin a fait l'objet en 1982 d'un mémoire de diplôme à l'Istituto centrale di restauro de Rome, dont les résultats sont synthétisés dans les actes du colloque organisé en 1985 sur ce jardin occupant un site archéologique fondamental (FAzzio et al., 1990), accompagnés de la publication d'un relevé du nymphée (GIOVANNETTI, 1990). Encaissée dans le flanc nord de la colline sur le parcours ascensionnel qui menait du portail d'entrée - initialement sur le Campo Vaccino avant qu'il ne soit remonté sur la Via di San Gregorio dans les années 1950 -, jusqu'au sommet du Palatin, la grotte hypogée, précédée d'un cryptoportique quadrangulaire, semble appartenir à la deuxième phase des travaux sous le cardinal Odoardo Farnese, entre 1591 et 1626 (MORGANTI, 2001, p. 173), et non à la première entre 1565 et 1589 comme on le pensait auparavant.

Moins spectaculaires dans leur décor minéral - mais non leurs jeux d'eau! - que leurs homologues florentines, les grottes des grandes villas aménagées dans le Latium dans la seconde moitié $\mathrm{du} \mathrm{XVI}^{\mathrm{e}}$ siècle n'ont pas suscité autant d'intérêt spécifique, mais sont évoquées dans les travaux sur les principaux jardins. On compte cinquante fontaines à la villa d'Este à Tivoli, aménagées de 1560 à 1572 pour le cardinal Hippolyte, parmi lesquelles bon nombre de grottes sur lesquelles les connaissances n'ont pas été bouleversées depuis vingt-cinq ans, mais affinées à la faveur des opérations de restauration qui ont donné lieu à des campagnes systématiques de relevés (PASQUINI BARISI, 2001 ; BARISI, FAGIOLO, MADONNA, 2003).

Pour le palais Farnèse de Caprarola, les travaux de Rosalba Cantone sur les archives, les descriptions anciennes et la documentation graphique ont permis de mieux caler la chronologie. L'ensemble comprend notamment la grotte de Vénus dans le jardin d'Été (créé entre 1557 à 1573), la grotte des Satyres attribuée à Giovanni Antonio Dosio dans le jardin d'Hiver (réalisé de 1573 à 1583), surmontée de la fontaine des Licornes, et le nymphée du Berger à l'articulation entre ces deux jardins bas, exécuté après 1583 (CANTONE, CIPOLLONE, 2001 ; CANTONE, 2003).

Enfin, certes modestes, les deux petites grottes de la villa Lante à Bagnaia, situées à l'arrière des deux pavillons principaux et abritant à l'est une Vénus dont l'eau s'écoule des seins, à l'ouest un Neptune brandissant un trident, ont été beaucoup moins commentées que les autres fontaines du jardin du cardinal Gianfrancesco Gambara, créé pour l'essentiel entre de 1568 et 1587, à propos duquel le colloque monographique de 2004 n'a pas tranché quant à l'attribution du projet d'ensemble à Vignole (FROMMEL, BARDATI, 2005a). Ces deux grottes participeraient d'une évocation de la fertilité de la nature, également incarnée par la fontaine des Fleuves (LAZZARO, 1990, p. 259-260). Il faut sans doute les relier à la mise en scène de la phénoménologie de l'eau sur l'axe principal du jardin, que mes propres recherches ont interprétée en fonction des théories météorologiques de l'époque, et y voir une allusion à la Terre et à l'Eau - la 
thématique des quatre éléments imprégnant tout le jardin (FAGIOLO, 1994) -, ou encore aux qualités chaude et humide, qui favorisent la génération dans la nature et que l'on peut symboliser par Vénus et Neptune selon les Ragionamenti accademici sopra alcuni luoghi difficili di Dante (1567) de Cosimo Bartoli (BRUNON, 2001a, vol. II, p. 643-644).

\section{Le reste de la péninsule}

L'ancienne République de Gênes, citée par le Trattato de Giovan Paolo Lomazzo aux côtés de Rome et de Fontainebleau - sans nommer Florence - au sujet de "l'uso d'ornare i fonti in diversi modi di belli edifici » (LOMAzzo, [1584] 1975, p. 300), constitue la troisième région d'Italie où les grottes artificielles connurent le développement le plus significatif à la Renaissance et pour laquelle on dispose de la série des travaux de Lauro Magnani (MAGNANI, 1985, 1987, [1987] 2005, p. 81-102, 1999 et 2001). Ces recherches furent initiées pour une exposition organisée en 1984 qui présentait les principaux exemples, analysait les techniques d'exécution de leurs riches décors de mosaïques et de coquillages et replaçait les grottes génoises dans leur contexte social, philosophique, scientifique et poétique (Tra Magia, scienza..., 1984). La préparation de cette manifestation fut l'occasion d'une belle découverte car une enquête sur le terrain permit de retrouver dans le soubassement d'un immeuble de la colline de Fassolo la « fonte del capitan Larcaro " attribuée par Vasari à l'architecte Gaelazzo Alessi, qui devait à l'origine appartenir à la famille Doria Galleani et que l'on croyait disparue. Le décor de l'espace principal, de plan octogonal couvert d'une coupole, se révèle bien conservé mais l'atrium est en grande partie détruit; une restauration se poursuit en vue de l'ouverture de cette grotte au public (staGno, 2002 et 2005, p. 122). Proche dans ses solutions formelles mais de plan elliptique, la grotte de la villa Pallavicino delle Peschiere sur la colline de Multedo, terminée vers 1562 (date d'une controverse à son sujet entre le sculpteur Giacomo da Valsoldo et le commanditaire Tobia Pallavicino) et légèrement postérieure, ne fut peut-être pas conçue par Alessi, auteur du palais, mais par Giovanni Battista Castello dit il Bergamasco (RossinI, 2002). Parmi les autres réalisations marquantes, la grotte Doria Pavese à Sampierdarena, édifiée à partir de 1594 par Camillo Pavese, comporte un espace central à huit arcades sous coupole entouré d'un bassin annulaire et ceint d'une paroi ornée de concrétions et creusée de niches, que Joseph Furttenbach interprétait en 1627 comme la représentation de la terre ferme circonscrite par l'océan (MARTINI, 2002). Gênes présente ainsi une riche tradition locale qui, au cours de la seconde moitié $d u \mathrm{XVI}^{\mathrm{e}}$ siècle, se détache de plus en plus des modèles antiques (MAGNANI, 1999, p. 317).

Les grottes de Vénétie au $\mathrm{xvI}^{\mathrm{e}}$ siècle avaient été négligées jusqu'à leur étude par Margherita Azzi Visentini (AZZI VISENTINI, 1990 et 2002a). L'une des plus anciennes serait la grotte construite par Ammannati vers 1546 pour la résidence Gualdo à Vicence, démolie en 1834. Deux projets de Daniele Barbaro probablement conçus au lendemain de son voyage dans la cité pontificale en 1554, la grotte du palais Trevisan de Murano et le nymphée de la villa de Maser, ont un caractère très "romain", le second, à l'iconographie complexe, faisant sans doute allusion à un sanctuaire décrit par Pausanias (AZZI VISENTINI, 2002b). Organisé en différents niveaux séparés par une grande falaise, le jardin du palais Giusti de Vérone, construit par le comte Agostino Giusti entre 1565 et 1580, comporte dans l'axe principal une grotte de plan rectangulaire, percée à la base de l'escarpement. Aujourd'hui disparu, le riche décor de nacre, coquillages, 
coraux et verres colorés qui agrémentait la grotte est connu par différents témoignages parmi lesquels un croquis annoté de l'architecte Heinrich Schickhardt datant de 1598, qui explique que les parois latérales étaient revêtues de paysages peints dans des fausses fenêtres et celle du fond de miroirs, donnant l'impression de se trouver dans une loggia ouverte sur les quatre côtés. Quatre autres grottes sont aménagées au pied de la falaise, dont celle dite des Échos, au plan octogonal complexe puisque les parois diagonales, dentelées d'angles droits aux arêtes saillantes, alternent avec des bras creusés de niches qui s'enfoncent sur les axes orthogonaux, cette disposition créant des effets acoustiques sophistiqués; bien que cette dernière construction ne soit pas documentée avant le XVIII ${ }^{e}$ siècle, la série des grottes du jardin Giusti pourrait faire allusion aux cinq sens (AZZI VISENTINI, 2002c).

En Lombardie, le cas du nymphée de la villa Borromeo Litta à Lainate près de Milan a été abordé par les recherches d'Alessandro Morandotti, qui a notamment analysé les liens de cet épisode "profane ", bien différent de l'art sacré alors promu par un Frédéric Borromée, avec le cercle artistique gravitant autour de Lomazzo (MORANDOTTI, 1985, 1998, 2000 et 2005). Commandée par Pirro I Visconti Borromeo, la construction fut achevée par l'architecte Martino Bassi en 1587 et la décoration à base de concrétions, coquillages et mosaïques, impliquant Camillo Procaccini, en était terminée en 1589. Restauré à partir de 1980, l'ensemble présente deux caractéristiques remarquables : la séquence de salles accueillait une collection de peintures, sculptures, automates et curiosités naturelles, composant un musée dont Vincenzo Scamozzi invita à suivre l'exemple ; par ailleurs, l'alimentation hydraulique se faisait en puisant dans la nappe phréatique grâce à un système de pompes actionnées par la force animale, et non par captation d'une source ou dérivation d'un cours d'eau comme dans la plupart des grottes contemporaines (ROSA, 2002).

Les grottes réalisées dans d'autres aires italiennes, notamment les cours princières, n'ont pas encore fait l'objet d'études d'ensemble, bien que de nombre de cas méritent l'attention comme les grottes de Girolamo Genga à la villa Imperiale de Pesaro, commencée en 1530 (MARTUFI, 2002), les espaces hypogées que Girolamo da Carpi réalisa dans les années 1540 au palais de la Montagne à Ferrare (CECCARELLI, 2004, p. 76-77), ou encore la grotte du jardin secret dans le palais du Te à Mantoue qui, longtemps attribuée à Jules Romain, date très probablement des années 1590 sous Vincent $\mathrm{I}^{\text {er }}$ Gonzague (BELLUZZI, 1987).

\section{Des approches techniques fécondes}

31 Si les nombreuses opérations de restauration promues en Italie ont permis de faire progresser les recherches documentaires, certains chantiers ont également donné lieu à des études archéologiques, qui améliorent notre connaissance matérielle des grottes artificielles. Les réalisations médicéennes ont particulièrement bénéficié de telles approches.

On compte tout d'abord la découverte de structures enfouies. L'un des cas les plus spectaculaires fut celui du pavement des allées du petit jardin qui précédait la Grande Grotte de Boboli, le long du corridor de Vasari, retrouvé par hasard lors de travaux sur des canalisations puis remis au jour en 1998 à la suite de sondages. Réalisé en mosaïque à partir de galets de couleur claire et sombre, il est orné de motifs géométriques, animaliers et héraldiques. La récupération du niveau initial a en outre dégagé le perron 
de la grotte, constitué de deux marches en pietra forte. Des recherches en archives ont rendu possible la datation de ces éléments constitutifs de l'ancien jardin associé à la grotte, réalisés à partir de 1557, et de leurs vicissitudes postérieures (BALDINI GIUSTI, 2003).

La grotte de Buontalenti a par ailleurs été auscultée par de multiples spécialistes : étude des types de mortiers et des canalisations internes des reliefs pariétaux de la première chambre (PIERELli, 1991); récupération de détails illisibles dans les peintures et confrontation entre les pigments utilisés dans la technique mixte de «tempera su fresco » et ceux indiqués par les documents (MEDRI, 1999, p. 222-224); inventaire systématique des espèces de coquillages utilisées dans la décoration, parmi lesquelles deux proviennent de la mer du Japon et de l'Afrique occidentale (BORRI, MARTIGNONI, VOLPI, 1999); analyse chimique et minéralogique des tesselles de verre et des mortiers de support des mosaïques (costagliola et al., 1999); identification iconographique des espèces animales peintes, dont quinze mammifères et près de soixante oiseaux dans la voûte de la première salle (ALTOBELLI, NISTRI, POGGESI, 1999). Certains de ces travaux, qui éclairent la complexité et le raffinement du décor, ont été menés en collaboration avec l'Université de Florence et le Museo di Storia Naturale.

Les chantiers lancés dans les années 1980 à Pratolino ont également été riches d'enseignements (bilan général dans BELISARIO, GROSSONI, ZANGHERI, 1999). Conduite entre 1985 et 1996, la restauration de l'Apennin conçu par Giambologna a été accompagnée d'approches archéologiques pluridisciplinaires qui en ont révélé «l'anatomie» (Risveglio di un colosso, 1988 ; VEzzosI, 1990). Autrefois abritée par un antre creusé dans une colline artificielle et elle-même creusée de grottes en partie détruites, la sculpture gigantesque a en fait été réalisée selon une technique d'exécution analogue à celle des grottes rustiques décrite par Vasari dans l'introduction des Vite sur l'architecture: appliqué sur une structure construite en maçonnerie de briques, le revêtement externe est constitué d'un enduit lisse figurant la peau, les cheveux et la barbe étant quant à eux rendus par un appareillage de concrétions et stalactites rattachées grâce à des éléments métalliques, d'où l'eau devait autrefois s'écouler par des canalisations (ACIDINI LUCHINAT, POZZANA, 1987 ; POZZANA, 1988 et 1990). On pourrait ainsi parler d'une grotte " inside out "... Un tel procédé visait à aboutir à l'image particulièrement expressive du colosse se métamorphosant en montagne. De plus, la restauration de la grotticina a impliqué la mise au point d'une technique particulière puisque les coquillages manquants ont été remplacés par des moulages en résine, afin que ces intégrations soient clairement identifiables (POZZANA, 1996 et 1999). Quant à la grotte de Cupidon, l'identification des matériaux effectuée en 1991 a mis en évidence la présence de coquillages fossiles, de fragments de quartz et de stalactites artificielles très particulières, réalisées en terre cuite vitrifiée, dont la surface « marmoréenne » devait enrichir la voûte de précieux reflets (POZZANA, 1991, p. 78). Ici aussi, la restauration a fait appel à des techniques modernes, avec l'installation d'une cellule photo-électrique pour déclencher les jeux d'eau, autrefois actionnés grâce à un système de contrepoids par le mouvement des spectateurs à partir d'une marche " piégée ".

La décoration des grottes artificielles est éminemment composite, ou comme le dit judicieusement la langue italienne, "polimaterica». Dès 1985, Cristina Acidini Luchinat avait entrepris de dresser le catalogue des principaux matériaux employés dans les grottes florentines $\mathrm{du} \mathrm{XVI}{ }^{\mathrm{e}}$ siècle : mosaïques à base d'éléments lithiques ou vitrifiés ; céramiques, maïoliques et porcelaines ; coquillages, nacre et coraux etc., en laissant de 
côté toute la diversité des roches - concrétions, pétrifications... - nécessitant la consultation de pétrographes (ACIDINI LUCHINAT, 1985 et 1990). Une étude des matériaux décoratifs a en outre été menée pour les grottes génoises, où la présence fréquente de tesselles de maïolique émaillée ou de pâte de verre renforce la vive polychromie (BENSI, 1987). Il serait souhaitable que les études postérieures sur ces aspects techniques fassent l'objet d'une tentative de synthèse, comme on l'a récemment proposé pour les matériaux utilisés dans les grottes françaises et leur mise en œuvre (couilLAux, 2004).

\section{Des problématiques culturelles complexes}

Cette richesse matérielle, si elle pose d'évidents problèmes de conservation, n'est pas l'une des moindres dimensions qui concourent aux multiples implications culturelles des grottes artificielles. Celles-ci s'avèrent en effet étroitement associées au phénomène du collectionnisme de naturalia, sur lequel les recherches se sont multipliées. On voit ainsi le grand-duc François I ${ }^{\mathrm{er}}$ de Médicis répondre en 1581 au duc Guillaume $\mathrm{V}$ de Bavière, faisant alors construire par Friedrich Sustris la grotte du Grottenhof à la Residenz de Munich, qu'il s'efforcera de lui fournir coquillages et concrétions dès que possible, ayant employé tout son stock à Pratolino; dix ans plus tôt, l'agent de son frère, le cardinal Ferdinand, s'étant mis en contact avec le fontainier Curzio Maccarone pour obtenir de belles pétrifications, annonçait finalement à son maître que les plus aptes à décorer une grotte, celles de la région de Tivoli, étaient malheureusement pillées par le cardinal Hippolyte d'Este pour ses propres jardins! (BAROCCHI, GAETA BERTELÀ, 1993, n 231, p. 210 et n 39, p. 42). La rareté des matériaux précieux, facteur de prestige des grottes, rendait leur réalisation d'autant plus difficile qu'à la différence des objets habituels des collections de «merveilles » - tel un nautile monté en carafe -, pouvant circuler à l'occasion de dons, ces éléments n'étaient plus disponibles une fois incrustés dans ces décors fixes : leur valeur d'échange s'annulait une fois consommée leur valeur d'usage. Si la grotte artificielle a souvent été rapprochée de la Wunderkammer - à partir de la « grotta » du château de Mantoue où, vers 1500 , Isabelle d'Este conservait ses objets précieux, mais dont la dénomination reste discutée (ZANGHERI, 1991b, p. 55 ; CASTELLI, 1999, p. 156) -, elle se rattacherait moins au paradigme de la collection proprement dite qu'à celui de la mosaïque (BRUNON, 2001a, vol. II, p. 394-415).

Que la mise en scène de l'eau et des pierres puisse faire écho aux théories scientifiques de l'époque, telle est l'hypothèse déjà ancienne (ACIDINI LUCHINAT, 1979) que Philippe Morel a voulu approfondir en s'interrogeant sur l'arrière-plan épistémologique des grottes artificielles. À partir de l'étude du vocabulaire concernant le revêtement minéral des grottes, notamment les termes génériques spugna ou pietra spugnosa qui désignaient les pierres d'aspect «spongieux» - formations calcaires (tartaro, congelazione, colatura d'acqua, etc.) ou roches volcaniques (asprone, tufo) -, l'auteur montre comment l'usage de ces matériaux adjoints aux coquillages et au déploiement des jeux d'eau correspond sur des points précis aux conceptions savantes de Georgius Agricola, Jérôme Cardan, Ulisse Aldrovandi ou Bernard Palissy sur la formation des minéraux et des fossiles. Au-delà de la mise en jeu d'un savoir sur la matière, les grottes artificielles, «lieu d'expérimentation et de projection de ces préoccupations scientifiques, où affleurent simultanément leur contrepartie mythique et leur revers fantasmatique », se veulent la "théâtralisation » d'une genèse dont la nature offre le 
modèle à l'artiste, en somme du mouvement même de la création (MOREL, 1990 et 1998, p. 39). La question des liens éventuels entre grottes artificielles et alchimie n'a en revanche pas encore été traitée de manière satisfaisante: si le motif de la caverne apparaît par exemple dans certaines illustrations de traités spécialisés, le parallèle entre la visualisation de la métamorphose dans les grottes architecturales et le principe même de la transmutation (sZAFRANSKA, 1989, p. 83) nécessiterait d'être précisément discuté en fonction des contextes. Les analyses de Ph. Morel sur les scherzi d'acqua, jeux d'eau destinés à surprendre et à tremper le visiteur (ZANGHERI, 1987a) comme supports d'une évocation du déluge, ont été prolongées à propos de Pratolino, dont les grottes participent d'un système de représentation complexe des phénomènes météorologiques comme l'orage ou le tremblement de terre (BRUNON, 2004b).

Mécanismes hydrauliques encore plus sophistiqués, les automates se rencontrent fréquemment dans les grottes italiennes de la seconde moitié $d u x v^{e}$ siècle, à la faveur d'une redécouverte des écrits de Héron d'Alexandrie (DEZZI BARDESCHI, 1985). Le problème de leur fonction symbolique, qui avait été posé par des travaux antérieurs (BATTISTI, [1962] 2005 ; RINALDI, 1979), a été repris par Ph. Morel, qui identifie dans ces machines un enjeu esthétique essentiel perçu dans certains témoignages de l'époque : elles réaliseraient l'imitation artificielle la plus accomplie du principe du vivant, manifestant l'expression d'une "conception de l'art et de la nature qui dérive d'une culture marquée par le néoplatonisme et la magie» (MOREL, 1987 et 1998, p. 121). Mes propres recherches ont plutôt mis en évidence le cadre aristotélicien des principaux textes rendant compte des automates (Francesco de'Vieri en 1586, Bernardino Baldi en 1589), en les replaçant dans le contexte de la réflexion sur les pouvoirs illusionnistes de l'image qui anime la pensée de l'art dans la seconde moitié $d u x v l^{e}$ siècle, au moment d'une active relecture de la Poétique (BRUNON, 1999a et 2006a). Patricia Falguières a de même attiré l'attention sur le rôle de la mimèsis dans l'épistémologie de la mécanique au XVI ${ }^{\mathrm{e}}$ siècle (FALGUIÈRES, 2006).

Les approches de l'esthétique des grottes rustiques ont été largement dominées par la question de la dialectique entre art et nature (LAZZARO, 1990, p. 57-62; TESTA, 1991, p. 45-51; MAUÉ, 1995 ; FRANKE, 2000a ; ENGEL, 2001), admirablement condensée dans la formule d'une lettre de Claudio Tolomei (1543) évoquant la fontaine dans le jardin d'Agabito Belluomo à Rome comme apparaissant tour à tour un «naturale artifizio » ou une « artifiziosa natura » (reproduite dans MACDOUGALL, 1978b, p. 12 ; AZZI VISENTINI, 1999, vol. I, p. 242). Les grottes semblent en particulier faire écho aux interrogations sur l'origine des arts et l'imitation des «images de la nature ", à travers l'intérêt pour les fossiles, chez Palissy notamment, et l'inflexion du non-finito de Michel-Ange dans les réalisations florentines de Tribolo et de Buontalenti; la Grande Grotte de Boboli renverrait ainsi à l'origine naturelle de l'architecture, la caverne, comme à son devenir, la ruine, de même qu'à l'équilibre toujours instable des substances prises entre la génération et la corruption (MOREL, 1998, p. 43-85 et 95-106 ; RINALDI, 1999).

Dispositifs où la représentation dynamique d'une nature matricielle s'imprègne de mystère et s'entremêle à l'évocation de l'antique, les grottes artificielles présentent des liens étroits avec l'imaginaire de la littérature et du théâtre (MACDOUGALL, 1972; MOURLOT, 1977), à travers une grande variété de motifs qui vont de la caverne infernale à l'antre des nymphes, du locus horridus au locus amœnus. Le Songe de Poliphile paraitt fournir certains prototypes féconds comme l'entrée de grotte traitée en arc de 
triomphe ou l'antre consacré à Vénus (PoLIzZI, 1998, p. 66-67). Des analogies précises se dessinent entre certaines réalisations, les descriptions de la poésie chevaleresque de l'Arioste ou du Tasse et les décors éphémères répondant à la catégorie de la scène satyrique, qui se multiplient à Ferrare notamment avec le développement de la pastorale (PIETROGRANDE, 1999 et 2004). Grottes construites et grottes feintes dans les scénographies s'influencent réciproquement (FAGIOLO, GIUSTI, CAZZATO, 1997, p. 138 et suiv.). Le régime de représentation décelable dans la grotticina de Boboli et le nymphée Vecchietti a d'autre part été rapproché de la notion de «topothésie» ou description d'un lieu fictif, figure rhétorique mentionnée par Cicéron à propos de l'Amaltheum d'Atticus, qui informerait la manière dont la grotte vise à célébrer son commanditaire (BRUNON, 2005). Dans le cas de Pratolino, une série de poèmes dédiés au grand-duc François $\mathrm{I}^{\text {er }}$ de Médicis, en grande partie inédits, permettent de mieux comprendre comment les multiples grottes du parc contribuaient, avec un certain nombre de figures sculptées, à créer l'atmosphère bucolique que les contemporains attendaient d'un jardin dans la seconde moitié du XVI ${ }^{\mathrm{e}}$ siècle (BRUNON, 2000).

41 Toutes ces contributions mériteraient de plus amples commentaires; les références citées montrent en tout cas que l'une des tendances majeures de la recherche depuis les années 1990, l'émergence d'une histoire culturelle des jardins pluridisciplinaire et attentive aux interactions entre les dimensions matérielles et symboliques (BRUNON, MOSSER, 2007), s'observe spécifiquement dans le domaine des grottes italiennes à la Renaissance.

\section{Grottes françaises : avancées monographiques}

Par comparaison, la bibliographie sur la France s'avère d'emblée plus pauvre (BRUNON, 2004c). S'il est possible de faire remonter l'étude des grottes artificielles de la Renaissance en France au moins aux travaux de Louis Dimier sur Primatice et Palissy (DIMIER, 1897, 1900 et 1934), c'est à un article publié par Lucile M. Golson en 1971 que l'on doit l'établissement d'un premier corpus des grottes architecturales et une esquisse de leur évolution à partir du cas précoce de la grotte des Pins. Sous l'impulsion des artistes de l'école de Fontainebleau et en premier lieu de Primatice, leur développement aurait été encouragé selon l'auteur par les idées de Serlio sur le « mode rustique ", tandis que les exemples monumentaux français auraient eu plus tard des répercussions en Italie, notamment chez Vasari dans le nymphée de la Villa Giulia et chez Vignole aux Orti Farnesiani (Golson, 1971). De son côté, Naomi Miller, prolongeant sa thèse sur les fontaines de la Renaissance française (MILLER, [1966] 1977), s'est interrogée sur la "signification" des grottes artificielles en France aux $\mathrm{XVI}^{\mathrm{e}}$ et $\mathrm{XVII}^{\mathrm{e}}$ siècles, en portant l'attention sur l'arrière-plan littéraire et philosophique de ces créations ; soulignant leurs liens avec l'univers du théâtre, l'auteur les rapporte surtout à des préoccupations «néo-platoniciennes » et décèle chez certaines d'entre elles une dimension religieuse (MILLER, 1978 et 1982, p. 51-58). Nourries de multiples références, ces réflexions opèrent cependant des rapprochements qui ne sont pas toujours suffisamment argumentés pour pouvoir entièrement convaincre. 


\section{L'absence d'inventaire systématique}

43 À la suite de ces deux contributions pionnières, aucune étude n'a vraiment tenté de vue d'ensemble du phénomène: l'ouvrage de William Howard Adams sur les jardins en France $d u \mathrm{XVI}^{\mathrm{e}}$ au $\mathrm{XVIII}^{\mathrm{e}}$ siècle se contente de rappeler les exemples les plus connus (ADAMS, [1979] 1980, p. 21-24); la synthèse de Kenneth Woodbridge sur le «style français » des jardins renonce même à traiter spécifiquement des grottes (WOODBRIDGE, 1986). Pourtant, comme en Italie, les problèmes posés par la conservation du patrimoine qui nous est parvenu (coullzaux, 2004) devraient stimuler l'intérêt des chercheurs.

Il s'agit à vrai dire d'un domaine relativement délaissé où les contributions restent dispersées, probablement en raison de la disparition de la plupart des réalisations, de la maigreur de la documentation repérée mais aussi d'un manque d'intérêt malheureusement persistant pour les jardins du $\mathrm{xVI}^{\mathrm{e}}$ siècle en France et plus généralement de la très faible représentation de ce champ de recherche en histoire de l'art à l'université. La situation contraste donc avec l'abondance des travaux sur les grottes de la péninsule, malgré les efforts menés depuis vingt-cinq ans pour recenser le patrimoine français en matière de jardins.

Il faut rappeler en effet qu'une opération nationale de pré-inventaire des jardins a été engagée à partir de 1982 ; cette collecte des informations a permis de repérer à la date de 2002 plus de dix mille parcs et jardins sur l'ensemble du territoire, dont la moitié sont considérés comme particulièrement remarquables ${ }^{6}$. Autrement dit, alors qu'il y a vingt-cinq ans les lieux à partir desquels s'élaborait l'historiographie des jardins ne se comptaient en France que par dizaines, c'est un immense corpus qui mérite aujourd'hui considération et dont on commence enfin à mesurer la richesse. Néanmoins, ce catalogage entrepris dans un contexte politique de décentralisation progressive s'avère géographiquement disparate dans ses moyens et son ampleur et n'a pas fait l'objet d'un recoupement systématique (BRUNON, 2006b). Une démarche collective comparable à celle qui a abouti à l'atlas thématique des grottes et des nymphées en Italie resterait donc à conduire.

L'étude des grottes de la Renaissance a surtout donné lieu, dans les dernières années, à des mises au point de type monographique. Aussi le bilan des travaux peut-il s'organiser en fonction des principales grottes connues, liées pour la plupart au milieu royal, selon une progression chronologique allant des années 1520 aux années 1580 plutôt que par classement topographique. Dans ce panorama, on verra que les incertitudes et les interrogations l'emportent largement sur les résultats définitivement acquis.

\section{Des grottes commandées par de puissants personnages}

47 L'un des exemples les plus précoces jusqu'ici repérés est fourni par Coussay (Vienne), prieuré que le prélat Denis Briçonnet fit transformer en « maison des champs » en 1520 à son retour de Rome. Outre le logis neuf, ouvert de tous côtés sur le paysage, l'ensemble comporte le pavillon de la Fontaine qui s'élève près de l'entrée, dont le rezde-chaussée, voûté d'ogives, s'ouvre par une grande arcade en anse de panier et abrite un bassin alimenté par une fontaine. Ce nymphée a pu être inspiré de modèles romains directement connus par son commanditaire (GUILLAUME, 2006, p. 147). 
Rien ne subsiste de la grotte aménagée pour Philippe Chabot, amiral de France, dans le parc de son château de Pagny (Côte-d'Or), reçu en dot en 1527 et rasé en 1774 à l'exception de la chapelle. Décorée de coquillages, de rochers, de fresques illustrant les Métamorphoses d'Ovide et d'une statue de Bacchus (DuBon, 1960, p. 6), elle aurait été la première grotte artificielle proprement dite en France (BABELON, 1989, p. 283).

Bien plus célèbre, la grotte des Pins fut construite pour François I ${ }^{\text {er }}$ vers 1543 à Fontainebleau (Seine-et-Marne), au rez-de-chaussée d'un pavillon situé à l'extrémité occidentale de la galerie d'Ulysse. Sa conception a été attribuée tour à tour à Serlio aujourd'hui écarté - et à Primatice, le second étant en tout cas l'auteur de deux dessins préparatoires pour les fresques de la voûte, des tondi représentant Minerve et Junon (Musée du Louvre, Département des arts graphiques, inv. 8551 et 8552), que la restauration conduite par Bernard Collette en 1980, peu scrupuleuse, a trop audacieusement restituées in situ, n'hésitant même pas à repeindre entièrement la fresque ovale centrale sans aucune base documentaire! Les recherches de Flaminia Bardati suggèrent toutefois que la façade, si elle dérive clairement des leçons de Jules Romain, traduit une interprétation formelle plus que structurelle de l'architecture rustique, et trahirait dès lors une approche française plutôt qu'italienne, que l'on peut rapprocher des expériences de Pierre Lescot et pour laquelle une intervention personnelle de François I ${ }^{\text {er }}$, passionné d'architecture, n'est pas à exclure (BARDATI, 1999, 2002, 2005 et 2006). Les quatre figures encastrées dans les piliers de la façade, complétées d'un terme à gauche - son pendant de droite a disparu -, ne sont pas véritablement des atlantes ou des télamons mais renvoient plutôt au type classique des prisonniers; présentant d'indéniables échos à de fameux antiques romains (Apollon, Laocoon, satyres du cortile della Valle), ils doivent être replacés dans le contexte des bronzes copiés du Belvédère entre 1541 et 1543 sous la direction de Vignole et de Primatice. Cette façade connaîtra d'ailleurs une postérité directe dans la cour de la maison Maillard de Dijon, commandée par Jean Maillard à Hugues Sambin en 1561. Les comptes concernant la grotte des Pins ne citent comme noms que ceux des exécuteurs: Antoine Jacquet pour un modèle en terre de la façade ; Domenico Fiorentino et Jean Leroux pour la décoration intérieure "façon de Grotesse»; Giovan Battista Bagnacavallo et Luca Penni pour les figurations végétales dans les fresques pariétales, que devaient compléter des stucs colorés plutôt que des coquillages ou des mosaïques (BARDATI, 2005, p. 270-271). Le décor reste difficilement lisible en raison des problèmes de conservation, ce qui rend délicate l'interprétation de cette grotte, paradoxalement privée de structures hydrauliques. Parmi les hypothèses avancées, celle selon laquelle cet ensemble associé au jardin dit des Pins (GUILlAUME, GRODECKI, [1978] 1980) fut implicitement consacré à Pan (avancée par MILLER, 1978, p. 190-192) pourrait d'ailleurs être approfondie en s'interrogeant sur le modèle éventuel de l'Arcadie de Sannazar, puisque le célèbre roman, qui accorde au motif de la grotte de Pan une place primordiale, venait d'être traduit par Jean Martin en 1544. En reprenant récemment l'attribution du projet à Primatice, Sabine Frommel a suggéré de voir dans les figures de la façade, dont la réalisation semble avoir atténué la terribilità michelangelesque, des satyres évoquant la fertilité naturelle dont la captivité symboliserait le contrôle des énergies impétueuses, la grotte complétant le cycle de la galerie d'Ulysse par une sorte d'expérience poétique de l'antre de la nymphe Calypso (FROMMEL, 2005, p. 77-85). Signalons en outre qu'une nouvelle restauration est aujourd'hui à l'étude afin notamment de résoudre les problèmes structuraux dont souffre l'édifice. 

à Rome entre 1546 et 1552, que fut réalisée, vers 1550, la grotte de La Bâtie (Loire). Si les archives font défaut, deux descriptions du début $d u$ xvII siècle permettent de comprendre que le décor mythologique, malgré une assez bonne conservation des mosaïques et de certains termes, est aujourd'hui incomplet en l'absence de sculptures antiques illustrant notamment les saisons. Relevant les figurations actuellement préservées, Dominique Poulain y souligne la présence de Pan et décèle des allusions au cortège de Bacchus, qui aurait incarné l'automne (Poulain, 1990). Le sens général échappe mais on pressent de possibles connotations religieuses puisque la grotte, au rez-de-chaussée du corps de logis, donne directement accès à la chapelle qui était richement ornée. Peu courante en France, cette disposition d'un lieu typiquement profane communiquant avec un lieu par essence sacré ne manque pas d'antécédents italiens (CHASTEL, 1989, p. 119-150) 7 .

51 Commande de Charles de Guise, cardinal de Lorraine, qui achète Meudon (Hauts-deSeine) en 1552 à son retour de Rome, le "palais de la Grotte » fut confié à Primatice. Célébré par Vasari et plusieurs fois gravé par Israël Sylvestre au milieu du XvII siècle, cet ensemble aujourd'hui disparu comprenait notamment un cryptoportique inséré dans un jeu de terrasses et surmonté d'un grand pavillon central, qui servait à la fois de grotte artificielle creusée dans la colline (animée par l'eau et décorée à la voûte par des peintures qui simulaient une pergola de verdure, ainsi que par des marbres, stucs, coquillages et rocailles), de cabinet d'antiques (dans la salle du premier étage, ornée de figures plafonnantes conçues par Primatice) et de belvédère pour contempler le paysage vallonné et boisé. La construction sur un relief tourmenté donna lieu à d'importants travaux de terrassement, reflétés dans le marché de nivellement en 1558, selon une véritable mise en scène de la topographie (Boudon, 1999, p. 152-154). L'édifice et sa situation ont fait l'objet d'un travail de restitution à partir d'un recoupement systématique des sources écrites et figurées (BOUREL LE GUILLOUX, 2004, 2005a, 2005b et 2006). Commentant, à l'aide de l'Épitre au cardinal de Lorraine (1556) et surtout du Chant pastoral (1559) de Pierre de Ronsard, l'inscription dédiant la grotte au repos et aux Muses d'Henri II, Anne-Marie Lecoq y voit «l'étape finale dans un processus qui caractérise le $\mathrm{xVI}^{\mathrm{e}}$ siècle : la mise en rapport de plus en plus étroit du roi de France et des Muses dans l'imaginaire monarchique ». Processus dont elle retrace la généalogie à partir de Louis XII et la cristallisation sous François I ${ }^{\mathrm{er}}$, montrant en outre sa convergence avec «toute la poétique et la mystique de la nature développée par la Pléiade, et par Ronsard en particulier " (LECOQ, 1996, p. 102 et 109). D'autre part, le témoignage de Gabriele Symeoni (1558), comparant Meudon à la villa de Tivoli où Hadrien avait fait représenter les provinces parcourues lors de ses voyages (BOUREL LE GUILLoux, 2006, vol. I, p. 75), laisse penser qu'un cycle de peintures topographiques évoquant les monuments de Rome était prévu dans le pavillon. réaliser par Philibert De l'Orme, en 1558, le pavillon de la Grotte à Montceaux-en-Brie (Seine-et-Marne). Également installé sur une déclivité de terrain, il devait servir de belvédère pour assister aux parties du jeu de mail situé en contrebas. Rien ne subsiste de ce bâtiment monumental et c'est essentiellement à partir du devis et marché passé avec l'architecte, datant de mai 1557, que Liliane Châtelet-Lange avait pu proposer une hypothèse de restitution graphique de cet édifice où, pour la première fois en France, apparaît la formule du premier étage à ordre colossal (pilastres composites) sur un 
socle à bossage, inspirée du palais Caprini de Bramante et appelée à une singulière fortune (CHÂTELET-LANGE, 1973). La lecture du marché de 1557 a été ultérieurement affinée (PÉROUSE DE MONTCLOS, 2000, cat. 106, p. 317) et une restitution plus précise du pavillon a été élaborée (BOUREL LE GUILLOUX, 2005a). Il faut en outre noter que, dans le soubassement, la salle octogonale aménagée en grotte avec niche arrondie devait comprendre des fontaines et qu'un " canal de pierre » était prévu pour l'évacuation des eaux selon le marché, mais la documentation jusqu'ici repérée n'en dit pas davantage sur l'éventuel décor figuratif.

Nous sommes un peu mieux renseignés sur les deux grands projets de Bernard Palissy pour le duc Anne de Montmorency et pour Catherine de Médicis, également disparus, dont Léonard $\mathrm{N}$. Amico a repris le dossier amorcé dès l'historiographie du XIX siècle (Amico, 1996, p. 46-81). Rien ne prouve clairement que l'ensemble décrit par Palissy dans l'Architecture et ordonnance de la grotte rustique (1563), livret dédié au connétable de France, ait effectivement été achevé ni qu'il ait concerné Écouen. On présume que l'artiste, qui travailla de 1556 à 1564 à la grotte décrite, récupéra une partie des moules et céramiques déjà exécutés dans son atelier parisien. Une confrontation du texte avec les nombreux fragments exhumés au XIX ${ }^{e}$ siècle ou découverts il y a vingt ans lors des fouilles du Grand Louvre (DUFAY et al., 1987) amène en tout cas Amico à penser qu'avec ses nombreuses figurations métamorphiques et naturalistes, l'œuvre était singulièrement dépouillée de toute référence mythologique. Il faudrait donc interpréter l'esthétique très particulière de ce projet dans le cadre essentiel des recherches personnelles de Palissy - question du moulage d'après nature, refus calviniste de la figuration humaine, etc. -, dont les enjeux religieux, scientifiques et philosophiques ont été abondamment commentés par différents travaux, encouragés par le quatrième centenaire de sa mort en 1990 (LECOQ, 1991 ; LESTRINGANT, 1992 ; PALISSY, [1563] 1996; MOREL, 1998, p. 34 et suiv.; FALGUIÈRES, 2004b). Aux Tuileries en revanche, Palissy - secondé par De l'Orme pour l'architecture - dut sans doute se plier aux exigences précises de Catherine de Médicis en matière d'iconographie. Par un examen attentif des fragments connus, Amico a pu en effet repérer des motifs suggérant des associations possibles aux Muses et à Hercule, tel le masque à tête de lion, autrement dit à des sujets omniprésents dans la symbolique des Valois et singulièrement dans leurs fêtes de cour, par exemple l'entrée d'Henri II à Rouen en 1550 ou la réception des ambassadeurs polonais aux Tuileries en 1573. D'après des paiements de 1570, une description de 1575 et l'inventaire après décès de la reine en 1589, la grotte fut bien construite, vraisemblablement du côté de la Seine, mais dut rapidement tomber en ruine. Le fameux Devys d'une grotte pour la Royne, mère du Roy doit être écarté des sources puisqu'il est maintenant clairement établi qu'il s'agit d'un apocryphe du $\mathrm{xIX}^{\mathrm{e}}$ siècle (BAUTIER, BRESC-BAUTIER, 1987). Quant au Dessin pour la grotte de Madame la Grand (cette appellation présente dans les annotations devant désigner l'une des épouses de Claude Gouffier, qui fut grand écuyer de France de 1546 à 1570), feuille provenant de la collection Destailleur et conservée à la Kunstbibliothek de Berlin, sa relation avec la grotte des Tuileries reste conjecturale. Jean-Marie Pérouse de Montclos estime d'ailleurs que cette coupe d'une vaste grotte hypogée pourrait provenir de De l'Orme et concerner l'hôtel de Boisy à Paris (actuel hôtel de Mayenne, 21 rue Saint-Antoine), appartenant alors à Claude Gouffier, qui y fit d'importants travaux en 1568 au moment de son mariage avec Claude de Baune (PÉROUSE DE MONTCLOS, 2000, p. 171 et cat. 28, p. 246-247). 
Bien des énigmes subsistent également au sujet du château de Maulnes-en-Tonnerois (Yonne), bâti pour Antoine de Crussol, duc d'Uzès, et documenté par un marché de 1566 pour la construction et surtout par une notice dans l'anthologie de Jacques Androuet du Cerceau (ANDROUet Du CERCEAU, [1576-1579] 1988, p. 163-167). Le problème de l'attribution du château reste très débattu: l'ombre de Serlio (MILLER, 1976) ou la silhouette de De l'Orme (PÉROUSE DE MONTCLOS, 2000, cat. 104, p. 312-316) résistent mal aux nouveaux éclairages apportés par le colloque consacré à Maulnes en 2001, sans qu'un candidat plus sérieux ait été avancé (PIEPER, 2006a ; voir en particulier FROMMEL, 2006). Cette rencontre correspondait à l'achèvement de la campagne de relevés menée par l'équipe de Jan Pieper, qui a souligné l'originalité du nymphée, salle voûtée rectangulaire s'ouvrant sur le jardin par un portail à bossage rustique bicolore au niveau d'un bassin qui aurait été entouré de gradins, au pied de la façade postérieure de cet imposant édifice de plan pentagonal (PIEPER, [1991] 1999). Ce nymphée ne conserve pas de décor particulier mais peut-être eut-on le projet - interrompu par la mort du propriétaire en 1572 ? - de l'intégrer à une mise en scène complexe de l'eau, qui aurait également impliqué la fontaine de l'escalier-puits central et d'autres salles voûtées de cet étage, traitées en grottes et éventuellement munies d'automates (PIEPER, 2006b et 2006c) ; peut-être même tout le troisième niveau (correspondant au rez-de-chaussée), aurait-il pu servir de thermes à l'antique tels que les concevait Guillaume Du Choul (1556) suivant une hypothèse suscitée par le témoignage d'Androuet du Cerceau, qu'a examinée Suzanne Traber dans sa thèse (TRABER, 2006). Toutefois, les études archéologiques qui ont suivi le rachat du château par le Conseil général de l'Yonne en 1997 invitent plutôt à penser que cet étage ne comportait qu'une étuve à hypocauste et une baignoire (HENRION, 2001 et 2004, p. 137-142). En revanche, le grand bassin associé au nymphée servit sans doute à la baignade et pourrait renvoyer soit aux modèles romains comme la restitution de l'antre de la nymphe Égérie par Francisco de Hollanda, soit aux sanctuaires de sources qui abondaient dans la région dès avant la conquête romaine (CHATENET, 2004, p. 196-199). Par ailleurs, les fouilles menées par Anne Allimant suggèrent que le bassin ne fut pas entouré d'emmarchements à la manière d'un théâtre, comme le figure Androuet du Cerceau, mais simplement d'un encaissement ceint d'un mur de terrasses (BÜTTNER, HENRION, 2004, p. 168-170). Le nymphée jouait un rôle fondamental dans la liaison du château et du jardin, puisqu'on ne pouvait accéder à ce dernier que par le soubassement du logis, en remontant ensuite jusqu'au niveau des parterres. «Le passage de l'obscurité à la lumière, la vision retardée du jardin, la station au bord du bassin aux reflets si différents de ceux du nymphée étaient autant de moments ineffables propres à marquer l'esprit » (BOUDON, 2004, p. 215).

C'est semble-t-il à des artistes italiens, comme l'indique sa correspondance, qu'Albert de Gondi, comte de Retz et maréchal de France, commanda vers 1582 l'exécution de la grotte de son château de Noisy-le-Roi. Déjà décrit en 1599, ce pavillon apparut plus tard en élévation, plan et coupe dans les gravures de Jean Marot; détruit en 1732, il a fait l'objet des recherches d'Hélène Couzy (couzy, 1977), qui n'ont été que ponctuellement complétées depuis lors. L'édifice était installé sur une zone de forte rupture de pente dans un système de jardins en terrasses, dont l'agencement topographique a été étudié par Françoise Boudon (BOUDON, 1999, p. 155). Un salon octogone, sur lequel se greffaient de petits cabinets, accueillait notamment un buffet de rocailles dont subsiste un dessin par l'architecte allemand Christophe Pitzler. L'état initial est très probablement rendu dans une coupe architecturale, qui figure un décor de congélations et de coquillages. 
Par rapport aux gravures de Marot, d'importantes différences de voûtement et l'absence de second étage laissent présumer des transformations ultérieures au XVII ${ }^{\mathrm{e}}$ siècle, vraisemblablement pour François Bossuet. En outre, ce précieux document reflèterait selon Amico l'émergence d'une tendance nouvelle de la grotte rustique, où s'affirment le goût " pour une grâce étudiée et une définition architectonique précise " (AMICO, 1996, p. 81).

\section{Perspectives de recherche}

56 À l'issue de ce rapide bilan des travaux sur les grottes françaises de la Renaissance, plusieurs pistes de recherche méritent d'être esquissées. Du point de vue typologique, les exemples étudiés manifestent généralement une solution particulière d'insertion au niveau inférieur d'une architecture, qu'il s'agisse d'un corps de logis comme à La Bâtie d'Urfé (où la grotte s'ouvre d'ailleurs sur la cour d'honneur et non sur le jardin) et à Maulnes, d'une aile à Fontainebleau, ou bien d'un pavillon indépendant qui vaut en luimême comme palais miniature, à Meudon et à Montceaux par exemple. En prolongeant l'hypothèse avancée par Lucile M. Golson (1971) et récemment reprise (BOUREL LE GUILLOUX, 2006, p. 95-98), on pourrait s'interroger sur l'éventuelle postérité de cette formule en Italie, où l'idée de traiter en grotte le soubassement d'un édifice semble ne faire son chemin que plus tardivement, que ce soit au palais du Jardin à Parme, dont la grotte, commencée en 1564, fut probablement projetée par Vignole (ADORNI, 1990 et 2002), ou chez Buontalenti à Pratolino, dans les années 1570 (BRUNON, 2001a, vol. I, p. 216-220), avant de connaître de singuliers développements dans l'architecture florentine au XVII ${ }^{\mathrm{e}}$ siècle avec la vogue des «camere fresche » directement intégrées à la résidence (PERONI, 1992a).

Ce qui suggère d'ailleurs d'aborder plus systématiquement les usages - baignades ? banquets? spectacles ? - auxquels ces coûteuses constructions si intimement associées à la demeure devaient être destinées. Les témoignages littéraires pourraient sans doute être sollicités avec profit, en suivant l'exemple du travail de Marie-Madeleine Fontaine sur les fonctions sociales de l'environnement des châteaux (FONTAINE, 1999). Le cas de Maulnes invite en particulier à enquêter sur les relations possibles entre grottes artificielles et pratiques du bain, thème souvent évoqué dans la peinture de l'école de Fontainebleau (ZERNER, 1996, p. 189-207 ; HOLLÄNDER, 2006). Ainsi pourrait-on confronter de ce point de vue les grottes à plan octogonal (Montceaux, Noisy) aux réalisations génoises de Galeazzo Alessi - la grotte Larcaro-Doria Galleani déjà citée, mais aussi le bain de la villa Grimaldi à Bisagno (MAGNANI, 1999) - et à l'un de leurs modèles présumés, le bain des nymphes dans Le songe de Poliphile, dont la version française, publiée par Jean Martin en 1546, comprend justement une gravure supplémentaire donnant l'élévation intérieure de cette structure à plan octogonal, indice d'un intérêt particulier du public français pour de tels éléments (BRUNON, 1999b).

En troisième lieu, les recherches menées par Danièle Duport sur le rôle du jardin dans la littérature française de la Renaissance ont signalé l'importance du motif de la grotte dans l'émergence d'une nouvelle esthétique naturaliste à partir des années 1560 , illustrée aussi bien dans les entrées triomphales que dans la poétique de l'antre sauvage chez Ronsard (DUPORT, 2000 et 2002). Ce sont justement les liens entre ce phénomène culturel et le développement des grottes de jardin que la lecture de Meudon proposée 
par Anne-Marie Lecoq a commencé à explorer et qu'il faudrait désormais approfondir (LECOQ, 1996).

59 Cette dernière étude a contribué en outre à mieux repérer la récurrence d'un répertoire iconographique que l'on retrouve dans de nombreux exemples, tels le Parnasse et les Muses ou encore Pan et l'univers pastoral. De ces sortes de topoï figuratifs, comparables à ceux que Claudia Lazzaro a mis en évidence dans le décor des jardins italiens de la Renaissance (LAZZARO, 1990), il reste à mieux comprendre comment les artistes - et les lettrés ayant pu les conseiller - les ont mobilisés et réajustés au service de puissants personnages, d'autant plus que les grottes connues se rattachent à un réseau de prestigieux commanditaires, parfois visiblement en émulation les uns avec les autres, et gardent pour certaines d'entre elles la trace de véritables discours symboliques dont la teneur, grâce à une approche contextuelle et à la découverte éventuelle de nouveaux documents, pourra peut-être se préciser.

\section{Ingénieurs et fontainiers au tournant des $\mathrm{XVI}^{\mathrm{e}}$ et $\mathrm{XVI \textrm {I } ^ { \mathrm { e } }}$ siècles}

Il convient enfin de brièvement signaler que les recherches se sont récemment multipliées sur les artistes et techniciens actifs au tournant des $\mathrm{XVI}^{\mathrm{e}}$ et $\mathrm{xvII}{ }^{\mathrm{e}}$ siècles, lesquels débordent le cadre chronologique strict de la Renaissance. La figure de Tommaso Francini, ingénieur formé à Pratolino et installé en France, où il fondera une prestigieuse dynastie d'hydrauliciens, a suscité des essais de synthèse (BRUNON, 2001b ; ROSTAING, 2004), tandis que de nouveaux documents ont été retrouvés sur son travail à Saint-Germain-en-Laye aux côtés de l'architecte Étienne Dupérac et du jardinier Claude Mollet (BRESC-BAUTIER, 1992 ; LURIN, [2003] 2004). Beaucoup moins célèbre, le sculpteurfontainier Jean Séjourné, qui intervint aux grottes de Saint-Germain et de Rueil, est l'un de ces indispensables auxiliaires spécialisés dans les décors de rocailles et de coquillages, dont les diverses compétences mais aussi l'activité de fournisseur de matériaux transparaissent dans son inventaire après décès (BRESC-BAUTIER, 1993).

61 Auteur entre autres des Raisons des forces mouvantes (1615), qui fournit de nombreux modèles de grottes, automates et orgues hydrauliques, Salomon de Caus voyagea en Italie avant de travailler aussi bien pour le compte des archiducs Albert et Isabelle au parc de la Warande sur le Coudenberg à Bruxelles, du prince Henri de Galles à Richmond ou Greenwich Palace que de l'Électeur Palatin à Heidelberg. Cet ingénieur et architecte a réveillé l'intérêt des chercheurs, notamment pour ses contributions à la mécanique (VÉRIN, 2000) et sa place fondamentale dans l'histoire de l'architecture du paysage (MORGAN, 2007 ; voir en outre FRANKE, 2000b ; DE JONGE, 2000) ${ }^{8}$.

\section{Le phénomène des grottes en Europe : au-delà de l'italianisme?}

Ce type de carrière internationale fut l'une des clés du succès des grottes dans le reste de l'Europe à partir du dernier quart du $\mathrm{XvI}^{\mathrm{e}}$ siècle, phénomène dont il est cependant difficile d'établir une chronologie et une géographie précises en l'état actuel des recherches, d'autant qu'il n'existe pratiquement pas de panorama transfrontalier en dehors de la thèse déjà ancienne de Barbara Rietzch concernant l'Italie, la France et l'Allemagne (RIETZSCH, 1987). 
L'un des rares spécialistes à avoir affronté le problème, Luigi Zangheri, avait proposé dès les années 1980 de l'aborder en fonction du rayonnement culturel de la cour médicéenne (ZANGHERI, 1985, 1986, 1987b et 2003, p.61-87). Par exemple, c'est à l'architecte toscan Giovanni Gargiolli, arrivé à Prague en 1574, que l'empereur Rodolphe II confia le projet d'une grotte pour son parc de Bubeneč, laquelle, construite entre 1588-1589 et 1594, subsiste toujours, avec un intérieur cylindrique couvert d'une voûte hémisphérique qui évoque un mausolée plutôt qu'une grotte artificielle (ZANGHERI, 2003, p. 64-66). Près de Salzbourg, la résidence de Hellbrunn, aménagée sous la direction du sculpteur et architecte tessinois Santino Solari à partir de 1612 pour le prince-archevêque Markus Sittikus von Hohenems, reprend nombre des motifs de Pratolino comme la grotte semblant s'effondrer (RAVA, 1970 ; BIGLER, 1996; Schloss Hellbrunn..., 1997). La déclinaison vers 1600 d'une panoplie iconographique à la fois restreinte et ubiquiste (grottes d'Orphée, de Galatée, de Neptune, automates figurant des forgerons, etc.) invite d'ailleurs à suggérer que l'« invention » des grottes puisait alors, sur un mode rhétorique, dans une réserve de véritables topoï, une démarche en tout cas revendiquée par le dominicain Agostino Del Riccio dans son traité manuscrit Agricoltura sperimentale (1595-1598), où il imaginait, selon les principes de l'ars memoriae, un jardin royal muni de trente-deux grottes directement inspirées des principales réalisations romaines et florentines, en constituant de la sorte un catalogue des lieux communs de l'art des jardins dignes d'être imités (HEIKAMP, 1981b ; BRUNON, 2002).

Cependant, comme c'est le cas pour bien d'autres domaines de l'histoire de l'architecture et de l'art en général, l'approche des grottes artificielles doit désormais éviter l'écueil qui consiste à n'aborder la Renaissance que par le prisme jadis commode, aujourd'hui insatisfaisant, de la diffusion de l'«italianisme». Certes, de nombreux exemples de grottes européennes peuvent être rattachés à l'intervention d'artistes de la péninsule. Ainsi en Espagne, dans l'une des résidences de Philippe II, la Casa de Campo près de Madrid (NAVASCuÉs, ARIZA, TEJERo, [1991] 1998), la galerie des Grottes, composée d'une série de salles voûtées en enfilade, fut réalisée dans les années 1560 par une équipe de peintres et stucateurs italiens sous la direction du sculpteur Giovanni Antonio Sormano, sans doute concepteur de l'ensemble plutôt que l'architecte royal Juan Bautista de Toledo, auteur du palais et des jardins (TEJERO VILLARREAL, 1999). On a également mis en lumière le rôle d'experts qui furent appelés pour leurs compétences artistiques et techniques dans les principales cours, même si les projets qui motivèrent leur venue n'aboutirent pas forcément. Grâce à une riche correspondance diplomatique, Caterina Pagnini vient par exemple de reconstituer l'expérience assez romanesque de Costantino de' Servi en Angleterre : requis par Henri de Galles auprès de la cour médicéenne à défaut d'obtenir les frères Francini retenus en France, l'architecte alors en route pour la Perse se fait attendre à Paris et, enfin arrivé à Londres en mai 1611, se voit aussitôt confier un vaste projet pour que le parc de Richmond surpasse Pratolino, avec un géant creusé de grottes qui aurait été trois fois plus grand que celui de Giambologna ; le Florentin supplante sur ce terrain Salomon de Caus, dame le pion à Inigo Jones quant à l'organisation des spectacles, reçoit de multiples commandes de portraits et réorganise tous les chantiers princiers, mais la fulgurante ascension du favori est brutalement interrompue par la mort prématurée d'Henri en novembre 1612 (PAGNINI, 2006 ; voir aussi EICHE, 1998). L'aventure en dit long sur les opportunités de carrière d'artistes italiens aussi polyvalents que l'avait été 
Buontalenti auprès de mécènes soucieux de rivaliser avec les splendeurs de Florence ou de Rome... Et pourtant, les grottes artificielles connurent bien des réinterprétations locales.

En Angleterre d'ailleurs, si le terme "grotto » dérivait de "grotta » et conservait une consonance italienne, l'exemple le plus ancien qui ait été récemment repéré, anticipant sur les grottes réalisées sous les Stuart par Salomon de Caus et son frère Isaac notamment (STRONG, [1979] 1998, p. 73 et suiv.; KNOX, 1999), se démarque sur plusieurs points des modèles ultramontains. C'est dès 1584 que Lord Burghley fit ainsi venir des pierres spéciales de St Vincent's Rock, sans doute ces «Bristol diamonds » qui allaient être employés dans de nombreuses grottes postérieures, pour aménager une vaste chambre de sa résidence de Theobalds (Hertfordshire); déjà décrite en 1592, elle est qualifiée de "grotto» en 1600. On y trouvait des automates, comme c'était alors la mode dans toute l'Europe, mais aussi un tapis de gazon (artificiel ?) et surtout deux cheminées. Ainsi adaptée au climat britannique, cette grotte était située dans le bâtiment principal (au premier étage ou au rez-de-chaussée), comme parfois en France, et non dans un édifice indépendant du jardin, formule qui n'apparaîtrait pas outreManche avant 1610 au jardin de Sir Francis Carew à Beddington (Surrey), certaines grottes servant en outre d'ermitage (HENDERSON, 2005, p. 164-167).

On n'oubliera pas non plus que même en Italie, il fut parfois fait appel à des intervenants étrangers, notamment pour les aspects techniques : la fontaine de l'Orgue à la villa d'Este de Tivoli impliqua à partir de 1567 des fontainiers français, Luc Leclerc et son neveu Claude Venard (PASQUINI BARISI, 2001, p. 301); pour la grotte du palais du Jardin à Parme, les Farnèse firent venir des hydrauliciens allemands (ADORNI, 2002, p. 328).

Alors qu'en 1581, un Guillaume V de Bavière tâchait, nous l'avons vu, de faire venir de Florence coquillages et spugne pour la grotte du Grottenhof à Munich, le recours à des matériaux disponibles localement s'observe ici et là. Dans les Pays-Bas méridionaux, le nouveau jardin de Charles III de Croÿ à Heverlee près de Louvain, aménagé entre 1599 et 1602, comportait une grotte contenue dans une aubette (petit pavillon servant de butte pour le tir à l'arc), avec des automates, des coquillages et des pierres semiprécieuses provenant d'Anvers. Au château de Boussu (Hainaut), les descriptions du début du XVII siècle citent au moins deux grottes également significatives. L'une, en partie réalisée en coquillages, était située dans un pavillon octogonal au milieu d'une île circulaire et comprenait des fontaines représentant les trois parties du monde - sans l'Amérique - ; l'autre, non clairement localisée, est dite " en haut forme d'homme », ce qui suggère qu'elle ressemblait à la grotte des Pins de Fontainebleau avec ses figures sculptées à la façade (DE JONGE, 1998, p. 196 et 210-211; DE JONGE, 1999).

De tels exemples montrent, comme cela a été établi pour la France, que des solutions très particulières, du point de vue typologique, architectural, décoratif ou encore iconographique, ne peuvent se rapporter simplement à des modèles italiens et qu'un vocabulaire pluriel se met en place à travers l'Europe, en fonction des artistes impliqués mais aussi, bien entendu, des attentes diverses des commanditaires. Voyages d'artistes, circulation de dessins et de gravures, échanges de matériaux et de savoirfaire etc.: toutes ces facettes du développement des grottes artificielles à l'échelle européenne s'avèrent irréductibles au seul critère - aujourd'hui battu en brèche par les orientations méthodologiques des sciences humaines relevant des transferts culturels d'une influence qui s'opérerait toujours dans le même sens. D'autant que la France a pu 
fournir assez tôt des modèles alternatifs aux formules proprement italiennes : en 1584, Lomazzo plaçait déjà Fontainebleau parmi les capitales de l'art des grottes artificielles. La pondération des différents modèles dans le phénomène des grottes européennes n'est pas forcément la même que celle de leur fortune critique.

À ce propos, le contraste entre l'ampleur et la consistance de la bibliographie sur les grottes de la péninsule d'une part, et la relative dispersion des études sur l'hexagone d'autre part, devrait d'ailleurs être considéré comme un indice de la cartographie des recherches sur l'histoire des jardins. On rappellera que jusqu'en 2004, date de la création de Polia, Revue de l'art des jardins, la discipline ne possédait pas en France de périodique spécialisé, à la différence du Royaume-Uni (Garden History, depuis 1972), des États-Unis (Journal of Garden History, fondé en 1981 et devenu en 1998 Studies in the History of Gardens \& Designed Landscape) ou de l'Allemagne (Gartenkunst, depuis 1989). Si, en Italie, la revue Arte dei giardini : storia e restauro n'a connu qu'une brève existence (1991-1993), la recherche reste constamment catalysée par des colloques spécialisés, facteur majeur dans l'importance de la production dans le domaine ${ }^{9}$. Alors qu'en France les approches archéologiques sur les jardins se sont récemment multipliées, il serait souhaitable que les études préalables aux opérations de restauration donnent davantage lieu à publication.

Par leurs coquillages nacrés, leurs mosaïques utilisant des scories colorées, leurs miroirs dissimulés parmi les pierres ou leurs eaux jaillissantes, les grottes offrent presque toujours une scintillante pénombre. Cette atmosphère, sombre mais non obscure comme le disait Boyceau, peut aussi servir de métaphore pour définir l'état des recherches à leur sujet. S'il ne s'agit plus d'un domaine totalement négligé, il est rarement mis en pleine lumière dans les programmes universitaires français ; nombre de réalisations disparues ne sont qu'entrevues à travers une maigre documentation, tandis que d'autres, vestiges négligés, ne sont toujours pas répertoriées. Néanmoins, dans cette situation relativement ténébreuse, se détachent les brillants éclats que produisent les lieux les plus connus et les mieux conservés. Que ces grottes célèbres ne soient pas l'arbre qui cache la forêt, mais continuent à motiver l'étude d'un phénomène qui a touché toute l'Europe de la Renaissance, en cristallisant bien des préoccupations du temps.

\section{BIBLIOGRAPHIE}

- ACIDINI LUCHINAT, 1979 : Cristina Acidini Luchinat, « Rappresentazione della natura e indagine scientifica nelle grotte cinquecentesche », dans FAGIOLO, 1979, p. 144-153.

- ACIDINI LUCHINAT, 1985 : Cristina Acidini Luchinat, « Le cornici delle acque », dans VEzzosI, 1985, p. 7-12.

- ACIDINI LUCHINAT, 1990 : Cristina Acidini Luchinat, «Per un catalogo dei materiali delle grotte artificiali nella Firenze del Cinquecento », dans MORGANTI, 1990, p. 537-559. 
- ACIDINI LUCHINAT, 1992 : Cristina Acidini Luchinat, « La Grotta degli Animali », dans Cristina Acidini Luchinat, Giorgio Galletti, Le Ville e i Giardini di Castello e Petraia a Firenze, Ospedaletto, 1992, p. 109-129.

- ACIDINI LUCHINAT, GARBERO ZORZI, 1991 : Cristina Acidini Luchinat, Elvira Garbero Zorzi éd., Boboli 90. Atti del Convegno Internazionale per la salvaguardia e la valorizzazione del Giardino, (colloque, Florence, 1989), 2 vol., Florence, 1991.

- ACIDINI LUCHINAT, MAGNANI, POZZANA, 1987 : Cristina Acidini Luchinat, Lauro Magnani, Mariachiara Pozzana éd., Arte delle grotte. Per la conoscenza e la conservazione delle grotte artificiali, (colloque, Florence, 1985), Gênes, 1987.

- ACIDINI LUChINAT, POZZANA, 1987 : Cristina Acidini Luchinat, Mariachiara Pozzana, « L’Appennino del Giambologna : uomo, grotta, palazzo (parte I e II) », dans ACIDINI LUCHINAT, MAGNANI, POZZANA, 1987, p. 95-107.

- ACIDINI LUCHINAT, RINALDI, 1979 : Cristina Cristina Acidini Luchinat, Alessandro Rinaldi éd., «Antologia », dans FAGIOLO, 1979, p. 228-258.

- ADAMS, (1979) 1980 : William Howard Adams, Les jardins en France, 1500-1800. Le rêve et le pouvoir, (New York, 1979), Paris, 1980.

- ADORNI, 1990 : Bruno Adorni, « I giardini farnesiani a Parma e a Piacenza », dans MORGANTI, 1990, p. 505-521.

- ADORNI, 2002 : Bruno Adorni, « Palazzo del Giardino a Parma », dans tUTTLE et al., 2002, p 327-329.

- ALBERTI, (1485) 2004 : Leon Battista Alberti, De re aedificatoria, (Florence, 1485) ; trad. fr. : L'art d'édifier, Pierre Caye, Françoise Choay éd., Paris, 2004.

- ALTOBELli, NISTRI, POGGESI, 1999 : Anna Altobelli, Annamaria Nistri, Marta Poggesi, « Gli animali dipinti della Grotta del Buontalenti in Boboli : un tentativo di identificazione », dans LAPI BALLERINI, MEDRI, 1999, p. 255-260.

- ALVAREZ, 1981 : Frank Joseph Alvarez, The Renaissance nymphaeum: its origins and its development in Rome and vicinity, (thèse de doctorat, Columbia University), New York, 1981.

- AMICO, 1996 : Léonard N. Amico, À la recherche du paradis terrestre. Bernard Palissy et ses continuateurs, Paris, 1996.

- Andrea Palladio e la villa veneta..., 2005 : Andrea Palladio e la villa veneta da Petrarca a Carlo Scarpa, Guido Beltramini, Howard Burns éd., (cat. expo., Vicence, Museo Palladio in palazzo Barbaran da Porto, 2005), Venise, 2005.

- ANDROUET DU CERCEAU, (1576-1579) 1988 : Jacques Androuet du Cerceau, Les plus excellents bastiments de France, (Paris, 1576-1579), David Thomson éd., Paris, 1988.

- AÑóN FELIÚ, 1998 : Carmen Añón Feliú éd., Felipe II : el Rey íntimo. Jardín y Naturaleza en el siglo XVI, (colloque, Aranjuez, 1998), Madrid, 1998.

- AÑóN, SANCHO, 1998 : Carmen Añón, José Luis Sancho éd., Jardín y Naturaleza en el reinado de Felipe II, Madrid, 1998.

- ANTELINI Donelli, 1995 : Simona Antelini Donelli éd., La Fontana dell'Organo nei giardini del Quirinale. Nascita, storia e trasformazione, Rome, 1995.

- AZZI VISENTINI, 1990 : Margherita Azzi Visentini, « La grotta nel giardino veneto del Cinquecento », dans MORGANTI, 1990, p. 561-585. 
- AZZI VISENTINI, 1999 : Margherita Azzi Visentini éd., L'arte dei giardini. Scritti teorici e pratici dal XIV al XIX secolo, 2 vol., Milan, 1999.

- AZZI VISENTINI, 2002a : Margherita Azzi Visentini, « L'architettura delle grotte tra Cinque e Settecento ", dans CAZZATO, FAGIOLO, GIUSTI, 2002, p. 224-227.

- AZZI VISENTINI, 2002b : Margherita Azzi Visentini, « Maser. Ninfeo di villa Barbaro », dans CAzZATo, FAGIOLO, GIUSTI, 2002, p. 253-257.

- AZZI VISENTINI, 2002c : Margherita Azzi Visentini, « Verona. Giardino Giusti », dans CAZZATo, FAGIOLO, GIUSTI, 2002, p. 258-260.

- BABELON, 1989 : Jean-Pierre Babelon, Châteaux de France au siècle de la Renaissance, Paris, 1989.

- BAgATti VAlSECCHI, 1987 : Pier Fausto Bagatti Valsecchi éd., Protezione e restauro del giardino storico, (colloque, Florence, 1981), Florence, 1987.

- BALDINI GIUSTI, 2003 : Laura Baldini Giusti, « Il 'giardino della Grotta' », dans Palazzo Pitti, 2003, p. 424-435.

- BARDATI, 1999 : Flaminia Bardati, « La grotte des Pins à Fontainebleau », dans LAPI BALLERINI, MEDRI, 1999, p. 39-47.

- BARDATI, 2000 : Flaminia Bardati, « Les bronzes d'après l'antique de Fontainebleau et la sculpture française au milieu du XVI ${ }^{\mathrm{e}}$ siècle ", dans Gazette des Beaux-Arts, CXXXVI, 2000, p. 159-168.

- BARDATI, 2002 : Flaminia Bardati, « Francesco Primaticcio, Jacopo Barozzi da Vignola, Bronzi dall'antico di Fontainebleau », « Francesco Primaticcio, Minerva », « Maestro L.D. (Léon Davent), Grottes des pins ", dans Tuttle et al., 2002, cat. 17 et 19-20, p. 134-137.

- BARDATI, 2005 : Flaminia Bardati, « La 'grotte des Pins' à Fontainebleau », dans FROMMEL, BARDATI, 2005b, p. 270-274.

- BARDATI, 2006 : Flaminia Bardati, « La grotte des Pins à Fontainebleau : suggestions italiennes et interprétations françaises », dans PIEPER, 2006a, p. 261-274.

- BARISI, FAGIOLO, MADONNA, 2003 : Isabella Barisi, Marcello Fagiolo, Maria Luisa Madonna, Villa d'Este, Rome, 2003.

- BAROCCHI, GAETA BERTELÀ, 1993 : Paola Barocchi, Giovanna Gaeta Bertelà éd., Collezionismo mediceo : Cosimo I, Francesco I e il Cardinale Ferdinando. Documenti 1540-1587, (Collezionismo e storia dell'arte. Studi e fonti, 2), Modène, 1993.

- BASILI, 2001 : Maria Cristina Basili, « Roma. Villa Giulia », dans CAZZATO, FAGIOLO, GIUSTI, 2001, p. $169-170$.

- BATTISTI, (1962) 2005 : Eugenio Battisti, L'antirinascimento, 2 vol., (Milan, 1962), Turin, 2005.

- BATTISTI, (1972) 2004 : Eugenio Battisti, « Natura Artificiosa to Natura Artificialis », dans Coffin, 1972, p. 1-36, republié sous le titre " Dalla 'natura artificiosa' alla 'natura artificialis' », dans Eugenio Battisti, Giuseppa Saccaro del Bufa éd., Iconologia ed ecologia del giardino e del paesaggio, (Giardini e paesaggio, 9), Florence, 2004, p. 3-50.

- BAUTIER, BRESC-BAUTIER, 1987 : Robert-Henri Bautier, Geneviève Bresc-Bautier, « Un faux du XIX siècle : 'Devys d'une grotte pour la Royne, mère du Roy' ", dans Revue de l'Art, 78, 1987, p. 84-85. - BELISARIO, GROSSONI, ZANGHERI, 1999 : Alessandro Belisario, Paolo Grossoni, Luigi Zangheri éd., Pratolino tra passato e presente, (Pratolino, Laboratorio di Meraviglie, 6), Florence, 1999. 
- BELluzZI, 1987 : Amedeo Belluzzi, « La Grotta di Palazzo Te a Mantova », dans ACIDINI LUCHINAT, MAGNANI, POZZANA, 1987, p. 49-57.

- BÉNETIÈRE, 2000 : Marie-Hélène Bénetière, Jardin : vocabulaire typologique et technique, Paris, 2000. - BENSI, 1987 : Paolo Bensi, « Osservazioni sui materiali decorativi di alcune grotte artificiali genovesi », dans ACIDINI LUCHINAT, MAGNANI, POZZANA, 1987, P 83-88.

- BIASION, 1987 : Piero Biasion, « Immagine fotografica ed immaginario delle grotte artificiali », dans ACIDINI LUCHINAT, MAGNANI, POZZANA, 1987, p. 93-94.

- BIGLER, 1996 : Robert R. Bigler, Schloss Hellbrunn : Wunderkammer der Gartenarchitektur, Vienne, 1996.

- BORRI, MARTIGNONI, VOLPI, 1999 : Marco Borri, Roberto Martignoni, Cecilia Volpi, « Decorazione a conchiglie della Grotta di Bernardo Buontalenti nel Giardino di Boboli a Firenze », dans LAPI BALLERINI, MEDRI, 1999, p. 240-246.

- BOUDON, 1999 : Françoise Boudon, « Jardins d'eau et jardins de pente dans la France de la Renaissance », dans GUILLAUME, 1999, p. 137-183.

- BOUDON, 2004 : Françoise Boudon, « Le jardin de Maulnes dans son temps », dans CHATENET, HENRION, 2004, p. 213-216.

- BOUREL LE GUILLOUX, 2004 : Christophe Bourel Le Guilloux, La Question de la restitution d'un projet architectural appliquée à un bâtiment disparu du XVI e siècle : la grotte de Meudon, mémoire de TPFE, École d'Architecture de Paris La Villette, 2004.

- BouRel Le Guilloux, 2005a : Christophe Bourel Le Guilloux, « 'Pour donner plaisir \& contentement' : la grotta all'antica in Francia negli anni Cinquanta », dans FROMMEL, BARDATI, 2005a, p. 230-243.

- BoURel LE GUilloux, 2005b : Christophe Bourel Le Guilloux, « Il castello e la grotta di Meudon », dans FROMMEL, BARDATI, 2005b, p. 283-303.

- BOUREL LE GUILLOUX, 2006 : Christophe Bourel Le Guilloux, Le "palais de la grotte » à Meudon au XVI siècle, mémoire de Master 2, École pratique des hautes études, 3 vol., Paris, 2006.

- BOYCEAU, 1638 : Jacques Boyceau de la Barauderie, Traité du jardinage selon les raisons de la nature et de l'art, Paris, 1638.

- BRAGANTINI, 1999 : Irene Bragantini, « L'acqua, il giardino e la grotta nel mondo romano tra l'età tardo-repubblicana e la prima età imperiale », dans LAPI BALLERINI, MEDRI, 1999, p. 20-24.

- BRESC-BAUTIER, 1992 : Geneviève Bresc-Bautier, « Fontaines et fontainiers sous Henri IV », dans Les arts au temps d'Henri IV, (colloque, Fontainebleau, 1989), Pau, 1992, p. 93-120.

- BRESC-BAUTIER, 1993 : Geneviève Bresc-Bautier, « Fugaces et factices collections... Les 'inventaires après décès', le cas de J. Séjourné, fontanier du Roy (1614) », dans Jacques Guillerme éd., Les collections : fables et programmes, (Amphion : études d'histoire des techniques, 4), Seysel, 1993, p. $145-151$.

- BRUNON, 1999a : Hervé Brunon, « L'artifice animé : sur l'esthétique maniériste de l'automate », danS LAPI BALLERINI, MEDRI, 1999, p. 164-179.

- BRUNON, 1999b : Hervé Brunon, « La réception du Poliphile dans les jardins italiens du XVI siècle : tentative de mise au point », dans Werner Oechslin, Gilles Polizzi éd., La réception européenne du 
Songe de Poliphile : littérature, jardin et architecture, (colloque, Mulhouse/Einsielden, 1999), à paraître.

- BRUNON, 2000 : Hervé Brunon, « La forêt, la montagne et la grotte : Pratolino et la poétique pastorale du paysage à la fin du Xvi ${ }^{\mathrm{e}}$ siècle », (Mélanges de l'École Française de Rome. Italie et Méditerranée, CXII, 2), 2000, p. 785-811.

- BRUNON, 2001a : Hervé Brunon, Pratolino : art des jardins et imaginaire de la nature dans l'Italie de la seconde moitié $\mathrm{du} \mathrm{XVI}{ }^{e}$ siècle, thèse de doctorat, Université de Paris-I Panthéon-Sorbonne, 5 vol., Paris, 2001.

- BRUNON, 2001b : Hervé Brunon, « Tommaso Francini (1571-1651)», dans Michel Racine éd., Créateurs de jardins et de paysages en France de la Renaissance au XXI ${ }^{e}$ siècle, I : De la Renaissance au début du XIXe siècle, Arles/Versailles, 2001, p. 38-42.

- BRUNON, 2002 : Hervé Brunon, «L'orizzonte enciclopedico : la catalogazione del sapere nel 'giardino di memoria' di Agostino Del Riccio », dans Giuliana Baldan Zenoni-Politeo, Antonella Pietrogrande éd., Il giardino e la memoria del mondo, (Giardini e paesaggio, 4) Florence, 2002, p. 59-75.

- BRUNON, 2004a : Hervé Brunon, « Du Songe de Poliphile à la Grande Grotte de Boboli : la dualité dramatique du paysage ", dans Polia, Revue de l'art des jardins, 2, 2004, p. 7-26.

- BRUNON, 2004b : Hervé Brunon, « 'Les mouvements des eaux de l'Univers' : Pratolino, jardin météorologique ", dans BRUNON, MOSSER, RABREAU, 2004, p. 33-53.

- BRUNON, 2004c : Hervé Brunon, « Grottes de la Renaissance en France : état de la question », dans Philippe Morel éd., Les décors profanes de la Renaissance française. Nouvelles hypothèses, (colloque, Paris, 2004), sur http://halshs.archives-ouvertes.fr/halshs-00138629.

- BRUNON, 2005 : Hervé Brunon, « Ut poesis hortus : l'imaginaire littéraire dans les jardins italiens $\mathrm{du} \mathrm{XVI}{ }^{\mathrm{e}}$ siècle ", dans Henriette Levillain éd., Poétique de la maison. La Chambre romanesque, le Festin théâtral, le Jardin littéraire, (colloques, Caen, 1999-2001), Paris, 2005, p. 155-175.

- BRUNON, 2006a : Hervé Brunon, « Ars naturans, ou l'immanence du principe : l'automate et la poétique de l'illusion au XVI ${ }^{\mathrm{e}}$ siècle », dans PIEPER, 2006a, p. 275-304.

- BRUNON, 2006b : Hervé Brunon, « Questions et méthodes de l'histoire des jardins en France », dans Lionella Scazzosi, Laura Sabrina Pelissetti éd., A 25 anni dalle Carte di Firenze : esperienze e prospettive, (colloque, Cinisello Balsamo, 2006), Florence, à paraître.

- BRUNON, MOSSER, 2007 : Hervé Brunon, Monique Mosser, «L'enclos comme parcelle et totalité du monde : pour une approche holistique de l'art des jardins ", dans Ligeia. Dossiers sur l'art, XX, 73-76, 2007, p. 59-75.

- BRUNON, MOSSER, RABREAU, 2004 : Hervé Brunon, Monique Mosser, Daniel Rabreau éd., Les Éléments et les métamorphoses de la nature. Imaginaire et symbolique des arts dans la culture européenne $\mathrm{du} \mathrm{XVI}{ }^{e} a u$ XVIII ${ }^{e}$ siècle, (colloque, Bordeaux, 1997), (Annales du Centre Ledoux, 4), Bordeaux/Paris, 2004.

- BURECA, 2001 : Agostino Bureca, « Genazzano. Ninfeo Colonna », dans CAZZATo, FAGIolo, GIUSTI, 2001, p. 253-255.

- BURY, 1990 : Michael Bury, « Giambologna's Fata Morgana Rediscovered », dans Apollo, CXXXI, 336,1990, p. $96-100$ et $142-143$.

- BÜTTNER, HENRION, 2004 : Stéphane Büttner, Fabrice Henrion, « Le jardin », dans CHATENET, HENRION, 2004, p. 165-170. 
- CANTONE, 2003 : Rosalba Cantone, « I giardini della Villa Farnese di Caprarola : loro evoluzione, fortuna critica e prospettive di recupero ", dans Christoph Luitpold Frommel, Maurizio Ricci, Richard J. Tuttle éd., Vignola e i Farnese, (colloque, Plaisance, 2002), Milan, 2003, p. 118-143.

- CANTONE, CIPOLLONE, 2001 : Rosalba Cantone, Rosanna G. Cipollone, « Caprarola. Giardini di palazzo Farnese », dans CAZZATO, FAGIOLO, GIUSTI, 2001, p. 320-325.

- CARRARA, 2006 : Francesca Carrara, « Il magnifico Bernardo Vecchietti, cortigiano e committente di un inedito epistolario privato ", dans Giambologna, 2006, p. 302-314.

- CASTELLI, 1991 : Patrizia Castelli, « Eros ed erotismo a Boboli », dans ACIDINI LUCHINAT, GARBERO ZORZI, 1991, vol. I, p. 155-169.

- CASTELLI, 1999 : Patrizia Castelli, «L'antro delle Ninfe », dans LAPI BALLERINI, MEDRI, 1999, p. 153-163.

- CAZZATO, faGIOLO, GIUSTI, 2001 : Vincenzo Cazzato, Marcello Fagiolo, Maria Adriana Giusti éd., Atlante delle grotte e dei ninfei in Italia: Toscana, Lazio, Italia meriodionale e isole, Milan, 2001.

- CAZZATO, faGiolo, GiUSTI, 2002 : Vincenzo Cazzato, Marcello Fagiolo, Maria Adriana Giusti éd., Atlante delle grotte e dei ninfei in Italia : Italia settentrionale, Umbria e Marche, Milan, 2002.

- CECCARELLI, 2004 : Francesco Ceccarelli, « Palazzi, castalderie e delizie. Forme degli insediamenti estensi nel Ferrarese tra Quattrocento e Cinquecento », dans Gli Este a Ferrara. Un castello per la città, Marco Borella éd., (cat. expo., Ferrare, Castello, 2004), Milan, 2004, p. 73-83.

- CENCI, 1992 : Elena Cenci, « 'L'antro delle ninfe' : significato ed evoluzione dall'Antichità al Cinqucento », dans NUVOLARI, 1992, p. 147-153.

- CHASTEL, (1968-1969) 1989 : André Chastel, Mythe et crise de la Renaissance, (Genève, 1968-1969), Genève, 1989.

- CHASTEL, 1989 : André Chastel, Culture et demeures en France au XVI siècle, Paris, 1989.

- CHÂTELET-LANGE, 1968 : Liliane Châtelet-Lange, « The Grotto of the Unicorn and the Garden of the Villa di Castello », dans The Art Bulletin, L/1, 1968, p. 51-58.

- CHÂTELET-LANGE, 1973 : Liliane Châtelet-Lange, « Philibert de l'Orme à Montceaux-en-Brie : le Pavillon de la Grotte », dans Architectura, 2, 1973, p. 153-170.

- CHATENET, 2004 : Monique Chatenet, « Maulnes et l'architecture de son temps », dans CHATENET, HENRION, 2004, p. 190-212.

- CHATENET, HENRION, 2004 : Monique Chatenet, Fabrice Henrion éd., Maulnes : archéologie d'un château de la Renaissance, Paris, 2004.

- COFFIN, 1972 : David R. Coffin éd., The Italian Garden, (colloque, Washington, 1971), Washington, 1972 .

- COFFIN, 1979 : David R. Coffin, The Villa in the Life of Renaissance Rome, Princeton, 1979.

- COFFIN, 1991 : David R. Coffin, Gardens and Gardening in Papal Rome, Princeton, 1991.

- COGORNO, 2002 : Luisa Cogorno, « Le grotte artificiali : metodologie di rilievo e di rappresentazione », dans CAZZATO, FAGIOLO, GIUSTI, 2002, p. 48-52.

- Colomo, 1997 : Maria Teresa Colomo, « La grotta di Fattucchia e la statua della Fata Morgana di Giambologna », dans Magnificenza alla corte dei Medici, 1997, p. 426-429. 
- Colomo, 1999 : Maria Teresa Colomo, « Il restauro del Ninfeo di Villa Vecchietti o Fonte di Fata Morgana : l'importanza delle fonti letterarie e iconografiche », dans LAPI BALLERINI, MEDRI, 1999, p. 107-113.

- colomo, 2001 : Maria Teresa Colomo, « Bagno a Ripoli. Ninfeo di villa Vecchietti », dans CAzzATo, FAGIOLO, GIUSTI, 2001, p. 59-60.

- CONFORTI, 1987a : Claudia Conforti, « Il rilievo architettonico degli apparati del giardino : esempi di grotte », dans ACIDINI LUCHINAT, MAGNANI, POZZANA, 1987, p. 25-30.

- CONFORTI, 1987b : Claudia Conforti, « La grotta 'degli animali' o ‘del diluvio' nel giardino di villa Medici a Castello », dans Quaderni di Palazzo Te, 6, 1987, p. 71-80.

- CONFORTI, 1990 : Claudia Conforti, « Il sonno, il sacro, il tempo : indagine fra grotte e spelonche nella cultura manierista », dans MORGANTI, 1990, p. 523-536.

- Costagliola et al., 1999 : Pilar Costagliola et al., « Grotta del Buontalenti : composizione chimica e mineralogica delle tessere vetrose e delle malte di supporto dei mosaici interni », dans LAPI BALLERINI, MEDRI, 1999, p. 247-254.

- Couillaux, 2004 : Benjamin Couillaux, La conservation des nymphées à décor de coquillages en France, mémoire d'étude de l'École du Louvre, 2 vol., Paris, 2004.

- couzy, 1977 : Hélène Couzy, « Le château de Noisy-le-Roi », dans Revue de l'Art, 38, 1977, p. 23-34. - DE JONGE, 1998 : Krista De Jonge, « Les jardins de Jacques Du Broeucq et de Jacques Hollebecque à Boinche, Mariemont et Boussu », dans AÑón FELIÚ, 1998, p. 191-220.

- DE JONGE, 1999 : Krista De Jonge, « L'environnement des châteaux dans les Pays-Bas méridionaux au XVI ${ }^{\mathrm{e}}$ siècle et au début du XVII ${ }^{\mathrm{e}}$ siècle », dans GUILLAUME, 1999, p. 185-206.

- DE JONGE, 2000 : Krista De Jonge, « Ein Netz von Grotten und Springbrunnen : die 'Warande' zu Brüssel um 1600 », dans Gärten und Höfe der Rubenszeit, 2000, p. 89-105.

- DEZZI BARDESCHI, 1985 : Marco Dezzi Bardeschi, « Le fonti degli automi di Pratolino », dans VezzosI, 1985, p. 13-24.

- DIMIER, 1897 : Louis Dimier, « Recherches sur la grotte du jardin des Pins à Fontainebleau », dans Annales de la société historique et archéologique du Gâtinais, XV, 1897, p. 72-91.

- DIMIER, 1900 : Louis Dimier, Le Primatice : peintre, sculpteur et architecte des Rois de France. Essai sur la vie et les ouvrages de cet artiste suivi d'un catalogue raisonné de ses dessins et compostions gravées, Paris, 1900.

- DIMIER, 1934 : Louis Dimier, «Bernard Palissy rocailleur, fontenier et décorateur de jardins », dans Gazette des Beaux-Arts, XII, 1934, p. 8-29.

- DöRING, 2001 : Marina Döring, « La nascita della rovina artificiale nel Rinasicmento italiano ovvero il 'Tempio in rovina' di Bramante a Genazzano », dans Francesco Paolo Di Teodoro éd., Donato Bramante: richerche, proposte, riletture, Urbino, 2001, p. 343-406.

- DUBon, 1960 : David DuBon, « The Chapel of the Château of Pagny ", dans Philadelphia Museum of Art Bulletin, LVI, 267, 1960, p. 3-36.

- DUFAy et al., 1987 : Bruno Dufay et al., «L'atelier parisien de Bernard Palissy », dans Revue de l'Art, 78, 1987, p. 33-57.

- DUPORT, 2000 : Danièle Duport, Les jardins qui sentent le sauvage : Ronsard et la poétique du paysage, (Cahiers d'Humanisme et Renaissance, 57), Genève, 2000. 
- DUPORT, 2002 : Danièle Duport, Le jardin et la nature. Ordre et variété dans la littérature de la Renaissance, (Travaux d'Humanisme et Renaissance, 358), Genève, 2002.

- EICHE, 1998 : Sabine Eiche, « Prince Henry's Richmond : the project by Costantino de' Servi », dans Apollo, 441, 1998, p. 10-14.

- ELAM, 2005 : Caroline Elam, « Annibale Caro, Giovanni Gaddi, and Marcello Cervini : Fountain Grottoes in Renaissance Rome », dans GASTON, REISS, 2005.

- ELET, 2005 : Yvonne Elet, « The Role of Water at Villa Madama », dans GASTON, REISS, 2005.

- ENGEL, 2001 : Julie Engel, Les grottes artificielles maniéristes à Florence dans la seconde moitié du XVI siècle et l'évolution du modèle médicéen au travers des exemples de Castello, Pratolino et Boboli, mémoire de maîtrise, Université François-Rabelais, Tours, 2001.

- FAGIoLo, 1979 : Marcello Fagiolo éd., Natura e artificio. L'ordine rustico, le fontane, gli automi nella cultura del Manierismo europeo, Rome, 1979.

- FAGIOLO, 1980 : Marcello Fagiolo éd., La Città effimera e l'universo artificiale del giardino. La Firenze dei Medici e l'Italia del '500, Rome, 1980.

- FAGioLo, 1994 : Marcello Fagiolo, «Struttura e significato di Villa Lante a Bagnaia », dans Alberta Campitelli éd., Ville e parchi storici. Storia, conservazione e tutela, Rome, 1994, p. 219-230.

- FAGIOLO, 1998 : Marcello Fagiolo, «I giardini papali del Vaticano e del Quirinale », dans Giardini Regali. Fascino e immagini del verde nelle grandi dinastie : dai Medici agli Asburgo, Monica Amari éd., (cat. expo.,Udine, Villa Manin di Passariano, 1998), Milan, 1998, p. 69-80.

- FAGIOLO, 2001 : Marcello Fagiolo, « Roma. Giardini del Quirinale », dans CAZZATO, FAGIOLO, GIUSTI, 2001, p. 190-194.

- FAGIolo, GIUSTI, CAZZATo, 1997 : Marcello Fagiolo, Maria Adriana Giusti, Vincenzo Cazzato, Lo specchio del paradiso. Giardino e teatro dall'Antico al Novecento, Cinisello Balsamo, 1997.

- FAGIOLO, MADONNA, 1990 : Marcello Fagiolo, Maria Luisa Madonna, Roma delle delizie. I teatri dell'acqua, grotte, ninfei, fontane, Milan, 1990.

- FALGUIÈRES, 2004a : Patricia Falguières, Le maniérisme. Une avant-garde au XVI ${ }^{e}$ siècle, Paris, 2004.

- FALGUIÈRES, 2004b : Patricia Falguières, « Extases de la matière. Note sur la physique des maniéristes ", dans BRUNON, MOSSER, RABREAU, 2004, p. 55-84.

- FALGUIÈRES, 2006 : Patricia Falguières, « Poétique de la machine », dans Philippe Morel éd., L'art de la Renaissance entre science et magie, (colloque, Paris, 2002), Paris, 2006, p.401-449.

- FAzzio et al., 1990 : Franco Fazzio et al., « Il Ninfeo della Pioggia », dans MORGANTI, 1990, p. 813-821.

- Fons Sapientice, 1977 : Fons Sapientice: Garden Fountains in Illustrated Books, Sixteenth-Eighteenth Centuries, Elisabeth B. MacDougall, Naomi Miller éd., (cat. expo., Washington, Dumbarton Oaks, 1977), Washington, 1977.

- FONTAINE, 1999 : Marie Madeleine Fontaine, « La vie autour du château : témoignages littéraires », dans GUILLAUME, 1999, p. 259-293.

- FRANKE, 2000a : Birgit Franke, « Natürliche Kunst und künstliche Natur : ein Beitrag zur Grottenkunst des 16. und frühen 17. Jahrhunderts », dans Hartmut Laufhütte éd., Künste und Natur in Diskursen der Frühen Neuzeit, (Wolfenbütteler Arbeiten zur Barockforschung, 35), Wiesbaden, 2000, II, p. 1075-1094. 
- FRANKE, 2000b : Birgit Franke, « '...zur Lust und Zierde der Palläst und Gärten' : Salomon de Caus und die Grottenkunst », dans Gärten und Höfe der Rubenszeit, 2000, p. 83-88.

- FROMMEL, (1969) 2003 : Christoph Luitpold Frommel, « Bramantes 'Ninfeo' in Genzzano », dans Römisches Jahrbuch für Kunstgechichte, XII, 1969, p. 137-160, republié sous le titre « Il 'ninfeo' di Bramante a Genazzano », dans Christoph Luitpold Frommel, Architettura alla corte papale nel Rinascimento, Milan, 2003, p. 215-239.

- FROMMEL, 2002 : Christoph Luitpold Frommel, « Villa Giulia a Roma », dans tUTTLE et al., 2002, p. 163-166.

- FROMMEL, 2005 : Sabine Frommel, « Primaticcio architetto in Francia », dans FROMMEL, BARDATI, 2005b, p. 74-193.

- FROMMEL, 2006 : Sabine Frommel, « Sebastiano Serlio und das Schloss von Maulnes », dans PIEPER, 2006a, p. 119-141.

- FROMMEL, BARDATI, 2005a : Sabine Frommel, Flaminia Bardati éd., Villa Lante a Bagnaia, (colloque, Viterbe, 2004), Milan, 2005.

- FROMMEL, BARDATI, 2005b : Sabine Frommel, Flaminia Bardati éd., Francesco Primaticcio architetto, Milan, 2005.

- GALLENI, 1991 : Rodolfo Galleni, « Per una ipotesi interpretativa del gruppo scultoreo di Vincenzo de' Rossi nella Grotta Grande di Boboli », dans ACIDINI LUCHINAT, GARBERO zORZI, 1991, vol. I, p. 47-56.

- GALLETTI, 1999 : Giorgio Galletti, « La genesi della Grotta Grande di Boboli », dans LAPI BALLERINI, MEDRI, 1999, p. 228-239.

- GALLETTI, 2001a : Giorgio Galletti, « Firenze. Giardino di Boboli, grotta Grande », dans CAZZATO, FAGIOLO, GIUSTI, 2001, p. 12-16.

- GALLETTI, 2001b : Giorgio Galletti, « Firenze, loc. Castello. Villa Medicea, grotta degli Animali », dans CAZZATO, FAGIOLO, GIUSTI, 2001, p. 45-51.

- GALLETTI, 2003 : Giorgio Galletti, « Il restauro ottocentesco della facciata della Grotta Grande di Boboli », dans Palazzo Pitti, 2003, p. 436-445.

- Gärten und Höfe der Rubenszeit, 2000 : Gärten und Höfe der Rubenszeit : im Spiegel der Malerfamilie Brueghel und der Künstler um Peter Paul Rubens, Ursula Härting éd., (cat. expo., Hamm, Städtisches Gustav-Lübcke-Museum/Mayence, Landesmuseum, 2000-2001), Munich, 2000.

- GASTON, REISS, 2005 : Robert W. Gaston, Sheryl E. Reiss éd., « Fountains, Grottos, and Waterworks in Early Modern Rome », dans The Renaissance Society of America Annual Meeting, (colloque, Cambridge, 2005 ; non publié).

- Giambologna, 2006 : Giambologna : gli dei, gli eroi. Genesi e fortuna di uno stile europeo nella scultura, Beatrice Paolozzi Strozzi, Dimitrios Zikos éd., (cat. expo., Florence, Museo Nazionale del Bargello, 2006), Florence/Milan, 2006.

- Il giardino d'Europa, 1986 : Il giardino d'Europa. Pratolino come modello nella cultura europea, Marco Dezzi Bardeschi, Alessandro Vezzosi, Luigi Zangheri éd., (cat. expo., Florence, Palazzo Medici Riccardi/ Pratolino, Villa Demidoff, 1986), Milan, 1986.

- GIOVAnNETTI, 1990 : Bruno Giovannetti, « Rilievo del Ninfeo della Pioggia », dans MORGANTI, 1990, p. 821-826. 
- GIUSTI, 1999 : Maria Adriana Giusti, « Il restauro del ninfeo di villa Buonvisi-Bottini a Lucca », dans LAPI BALLERINI, MEDRI, 1999, p. 201-212.

- GIUSTI, 2001 : Maria Adriana Giusti, « Lucca. Ninfeo di villa Buonvisi-Bottini », dans CAZZATO, FAGIOLO, GIUSTI, 2001, p. 85-86.

- GIUSTI, 2004 : Maria Adriana Giusti, « Il panorama degli Elementi in una serie di grotte toscane », dans BRUNON, MOSSER, RABREAU, 2004, p. 237-243.

- GoLSON, 1971 : Lucile M. Golson, « Serlio, Primaticcio and the architectural grotto », dans Gazette des Beaux-Arts, LXXVII, février 1971, p. 95-108.

- GUILLAUME, 1999 : Jean Guillaume éd., Architecture, jardin, paysage. L'environnement du château et de la villa aux XVe et XVI siècles, (colloque, Tours, 1992), Paris, 1999.

- GUILlaume, 2006 : Jean Guillaume, « Un prélat aux champs : Denis Briçonnet à Coussay », dans Monique Chatenet éd., Maisons des champs dans l'Europe de la Renaissance, (colloque, Maisons, 2003), Paris, 2006, p. 145-150.

- GUILLAUME, GRODECKI, (1978) 1980 : Jean Guillaume, Catherine Grodecki, « Le jardin des Pins à Fontanebleau », dans Bulletin de la Société de l'Histoire de l'Art français, (1978) 1980, p. 41-51.

- HEIKAMP, 1964 : Detlef Heikamp, « L'architecture de la métamorphose », dans L'œeil, 114, juin 1964, p. 2-9.

- HEIKAMP, 1965 : Detlef Heikamp, « La Grotta Grande del giardino di Boboli », dans Antichità viva, IV/4, 1965, p. 27-43.

- HEIKAMP, 1969a : Detlef Heikamp, « Les Merveilles de Pratolino », dans L'œil, 171, mars 1969, p. 16-27 et 74-75.

- HEIKAMP, 1969b : Detlef Heikamp, « Pratolino nei suoi giorni splendidi », dans Antichità viva, VIII/ 2, 1969, p. 14-34.

- HEIKAMP, 1978 : Detlef Heikamp, « The 'Grotta Grande' in the Boboli Garden, Florence. A drawing in the Cooper Hewitt Museum, New York », dans The Connoisseur, CX-CXI, 799, 1978, p. 38-43.

- HEIKAMP, 1981a : Detlef Heikamp, « The grotto of the Fata Morgana and Giambologna's marble Gorgon », dans Antichità viva, XX, 3, 1981, p. 12-31.

- HEIKAMP, 1981b : Detlef Heikamp, « Agostino del Riccio, 'Del giardino di un re' », dans RAGIONIERI, 1981, p. 59-123.

- HEIKAMP, 1997 : Detlef Heikamp, « Giambologna, Fata Morgana », dans Magnificenza alla corte dei Medici, 1997, cat. 18, p. 51-52.

- HEIKAMP, 2003 : Detlef Heikamp, «L'interno della Grotta Grande del Giardino di Boboli », dans Palazzo Pitti, 2003, p. 446-475.

- HEIKAMP, 2006 : Detlef Heikamp, « Uccelli di bronzo », dans Giambologna, 2006, cat. 50, p. 249-252. - HENDERSON, 2005 : Paula Henderson, The Tudor House and Garden: Architecture and Landscape in the Sixteenth and Early Seventeenth Century, New Haven/Londres, 2005.

- HENRION, 2001 : Fabrice Henrion, « L'apparentement des bains du château de Maulnes : analyse archéologique des sols et des élévations ", dans Bulletin Monumental, CLIX/1, 2001, p. 77-89.

- HENRION, 2004 : Fabrice Henrion, « Le logis », dans CHATENET, HENRION, 2004, p. 106-152. 
- HOLLÄNDER, 2006 : Hans Holländer, « Der Quell und die Metaphern der Schönheit », dans PIEPER, 2006a, p. 191-207.

- KNox, 1999 : Tim Knox, « 'Complicated Beauties': the Artificial Grotto in England, c. 1600 to the Present Day », dans LAPI BALLERINI, MEDRI, 1999, p. 48-60.

- KRIS, (1926) 2005 : Ernst Kris, « Der Stil ‘Rustique’. Die Verwendung des Naturabgusses bei Wenzel Jamnitzer und Bernard Palissy ", dans Jahrbuch der Kunsthistorischen Sammlungen in Wien, Neue Folge, I, 1926, p. 137-208 ; trad. fr. : Le style rustique. Le moulage d'après nature chez Wenzel Jamnitzer et Bernard Palissy, Patricia Falguières éd., Paris, 2005.

- LAPI BALLERINI, 1999 : Isabella Lapi Ballerini, « Niccolò Tribolo e la Grotta degli Animali a Castello », dans LAPI BALLERINI, MEDRI, 1999, p. 268-283.

- LAPI BALLERINI, MEDRI, 1999 : Isabella Lapi Ballerini, Litta Maria Medri éd., Artifici d'acque e giardini. La cultura delle grotte e dei ninfei in Italia e in Europa. Atti del V Convegno Internazionale sui Parchi e Giardini Storici, (Florence/Lucques, 1998), Florence, 1999.

- LAVAGNE, 1988 : Henri Lavagne, 'Operosa antra'. Recherches sur la grotte à Rome de Sylla à Hadrien, (Bibliothèque des Écoles françaises d'Athènes et de Rome, 272), Rome, 1988.

- LAZZARO, 1990 : Claudia Lazzaro, The Italian Renaissance Garden, NewHaven/Londres, 1990.

- LAZZARO, 1995 : Claudia Lazzaro, « Animals as Cultural Signs: A Medici Menagerie in the Grotto of Castello ", dans Claire Farago éd., Reframing the Renaissance: Visual Culture in Europe and Latin America 1450-1650, New Haven/Londres, 1995, p. 197-227.

- LECOQ, 1991 : Anne-Marie Lecoq, « Le jardin de la Sagesse de Bernard Palissy », dans MOSSER, TEYSSOT, (1990) 1991, p. 65-76.

- LECOQ, 1996 : Anne-Marie Lecoq, “ 'Quieti et musis Henrici II. Gall. R.'. Sur la grotte de Meudon », dans Marc Fumaroli, Philippe-Joseph Salazar, Emmanuel Bury éd., Le Loisir lettré à l'âge classique, (colloque, Cerisy, 1993), Genève, 1996, p. 93-115.

- LESTRINGANT, 1992 : Frank Lestringant éd., Bernard Palissy 1510-1590 : l'écrivain, le réformé, le céramiste, (colloque, Saintes, 1990), Mont-de-Marsan, 1992.

- LOIZEAU, 2003 : Emmanuelle Loizeau, La Grotte de coquillages de Coulommiers. Chapelle des Capucins, Coulommiers, 2003.

- LOMAzzo, (1584) 1975 : Giovan Paolo Lomazzo, Trattato dell'arte della pittura, scoltura et architettura, (Milan, 1584), dans Giovan Paolo Lomazzo, Scritti sulle arti, (Robert Paolo Ciardi éd.), II, Florence, 1975.

- LURIN, (2003) 2004 : Emmanuel Lurin, « La belle vue de Saint-Germain-en-Laye. Nouveaux documents sur les jardins en terrasses construits sous le règne d'Henri IV », dans Bulletin de la Société de l'Histoire de l'Art français, (2003) 2004, p. 9-31.

- MACDOUGALL, 1972 : Elisabeth B. MacDougall, « Ars Hortulorum: Sixteenth-Century Garden Iconography and Literary Theory in Italy », dans CoFFIN, 1972, p. 37-59 (repris dans MACDOUGALL, 1994, p. 89-111).

- MACDOUGALl, 1978a : Elisabeth B. MacDougall éd., Fons Sapientiae: Renaissance Garden Fountains, (colloque, Washington, 1977), Washington, 1978.

- MACDOUGALL, 1978b : Elisabeth B. MacDougall, «Introduction », dans MACDOUGALL, 1978a, p. 1-14. 
- MACDOUGALL, 1978c : Elisabeth B. MacDougall, « 'L'Ingegnioso Artifizio': Sixteenth-Century Garden Fountains in Rome », dans MACDOUGALL, 1978a, p. 85-114 (repris dans MACDOUGALL, 1994, p. 57-87).

- MACDOUGALL, 1994 : Elisabeth B. MacDougall, Fountains, Statues, and Flowers: Studies in Italian Gardens of the Sixteenth and Seventeenth Centuries, Washington, 1994.

- MAGNANI, 1985 : Lauro Magnani, «'L'uso d'ornare i fonti'. Galeazzo Alessi and the construction of grottoes in Genoese gardens ", dans Journal of Garden History, V/2, 1985, p. 135-153.

- MAGNANI, 1987 : Lauro Magnani, « Dalla riscoperta al recupero ninfei e grotte artificiali tra città e villa », dans ACIDINI LUCHINAT, MAGNANI, POZZANA, 1987, p. 43-46.

- MAGNANI, (1987) 2005 : Lauro Magnani, Il Tempio di Venere. Giardino e villa nella cultura genovese, (Gênes, 1987), Gênes, 2005.

- MAGNANI, 1999 : Lauro Magnani, « Fortuna e continuità di un'immagine della natura : grotte in Liguria tra la seconda metà del Cinquecento e il primo Seicento ", dans LAPI BALLERINI, MEDRI, 1999, p. 308-320.

- MAGNANI, 2001 : Lauro Magnani, « Introduzione alle grotte dei giardini genovesi », dans CAZZATO, FAGIOLO, GIUSTI, 2002, p. 38-47.

- Magnificenza alla corte dei Medici, 1997 : Magnificenza alla corte dei Medici. Arte a Firenze alla fine del Cinquecento, (cat. expo., Florence, Palazzo Pitti, Museo degli Argenti, 1997-1998), Milan, 1997.

- MARTINI, 2002 : Paola Martini, « Genova-Sampierdarena. Grotta Pavese », dans CAZZATO, GAGiolo, GIUSTI, 2002.

- MARTUfi, 2002 : Roberta Martufi, « Pesaro, villa Imperiale », dans CAZZATo, FAGiolo, GIUSTI, 2002, p. 373-374.

- MAUÉ, 1995 : Claudia Maué, « 'Künstliche und artige Unordnung' : Naturalien und Naturimitationen in künstlichen Grotten des 16.-18. Jahrhunderts », dans Anzeiger des Germanischen Nationalmuseums, LXXVIII, 1995, p. 76-92.

- MEDRI, 1999 : Litta Maria Medri, « Considerazioni intorno alle prime fasi costruttive della Grotta Grande nel Giardino di Boboli », dans LAPI BALLERINI, MEDRI, 1999, p. 215-227.

- MEDRI, 2003 : Litta Maria Medri, « Le grotte », dans Litta Maria Medri éd., Il giardino di Boboli, Sienne, 2003, p. 68-99.

- MILLER, (1966) 1977 : Naomi Miller, French Renaissance Foutaines, (thèse de doctorat New York University, 1966), New York, 1977.

- MILLER, 1976 : Naomi Miller, « Musings on Maulne: Problems and Parallels », dans The Art Bulletin, LVIII, 2, 1976, p. 196-214.

- MILLER, 1978 : Naomi Miller, « Domain of Illusion: The Grotto in France », dans MACDOUGALL, 1978a, p. 175-206, republié dans PIEPER, 2006a, p. 223-259.

- MILLER, 1982 : Naomi Miller, Heavenly Caves. Reflections on the Garden Grotto, New York, 1982.

- MORANDOTTI, 1985 : Alessandro Morandotti, « Nuove tracce per il tardo Rinascimento italiano: il ninfeo-museo della Villa Borromeo, Visconti Borromeo, Litta, Toselli di Lainate », dans Annali della Scuola normale superiore di Pisa, Classe di lettere e filosofia, XV/1, 1985, p. 129-185.

- MORANDOTTI, 1998 : Alessandro Morandotti, « Il ninfeo di Lainate, i Rabisch e la Milano sperimentale dei giochi d'acqua ", dans Rabisch : il grottesco nell'arte del Cinquecento. L'Accademia 
della Val di Blenio, Lomazzo e l'ambiente milanese, Giulio Bora, Manuela Kahn-Rossi, Francesco Prozio éd., (cat. expo., Lugano, Museo cantonale d'Arte, 1998), Milan, 1998, p. 89-100.

- MORANDOTTI, 2000 : Alessandro Morandotti, « Il tempio dell'acqua : il ninfeo di Lainate », dans FMR, 143, 2000, p. 17-52.

- MORANDOTTI, 2005 : Alessandro Morandotti, Milano profana nell'età dei Borromeo, Milan, 2005.

- MOREL, 1987 : Philippe Morel, « Osservazioni sugli automi nel loro rapporto con le grotte, alla fine del Rinascimento », dans ACIDINI LUCHINAT, MAGNANI, POZZANA, 1987, p. 59-64 (repris dans MOREL, 1998, p. 107-121).

- MOREL, 1990 : Philippe Morel, « La théâtralisation de l'alchimie de la nature. Les grottes artificielles et la culture scientifique à Florence à la fin du XVI siècle ", dans Symboles de la Renaissance, III, Paris, 1990, p. 154-183 (repris dans MOREL, 1998, p. 5-106)

- MOREL, 1998 : Philippe Morel, Les grottes maniéristes en Italie au XVI ${ }^{e}$ siècle. Théâtre et alchimie de la nature, Paris, 1998.

- MORGAN, 2007 : Luke Morgan, Nature as Model: Salomon de Caus and Early Seventeenth-Century Landscape Design, Philadelphie, 2007.

- MORGANTI, 1990 : Giuseppe Morganti éd., Gli orti farnesiani sul Palatino, (colloque, Rome, 1985), (Roma Antica, 2), Rome, 1990.

- MORGANTI, 2001 : Giuseppe Morganti, « Roma. Orti Farnesiani », dans CAZZATO, FAGIOLO, GIUSTI, 2001, p. 172-177.

- MORYSON, (1617) 1907-1908 : Fynes Moryson, An Itinerary Containing His Ten Yeeres Travell, (Londres, 1617), 4 vol., Glasgow, 1907-1908.

- MOSSER, TEYSSOT, (1990) 1991 : Monique Mosser, Georges Teyssot éd., Histoire des jardins de la Renaissance à nos jours, (Milan, 1990), Paris, 1991.

- MOURLOT, 1977 : Élisabeth Mourlot, « 'Artifice naturel' ou ‘nature artificielle' : les grottes médicéennes dans la Florence du XvI ${ }^{\mathrm{e}}$ siècle ", dans Danielle Boillet et al., Ville et campagne dans la littérature italienne de la Renaissance. II. Le courtisan travesti, Paris, 1977, p. 303-342.

- NAVASCUÉs, ARIZA, TEJERO, (1991) 1998 : Pedro Navascués, María del Carmen Ariza, Beatriz Tejero, « La Casa del Campo », dans Joachín Fernández Pérez, Ignacio González Tascón éd., A Propósito de la Agricultura de jardines de Gregrorio de los Ríos, Madrid, 1991, p. 137-159, republié sous le titre « La Casa de Campo », dans AÑón, 1998, p. 421-439.

- NEUERBURG, 1965 : Norman Neuerburg, L'Architettura delle fontane e dei ninfei nell'Italia antica, (Memorie dell'Accademia di archeologia lettere e belle arti di Napoli, 5), Naples, 1965.

- NUVOLARI, 1992 : Francesco Nuvolari éd., Il Giardino storico all'italiana, (colloque, Saint Vincent, 1991), Milan, 1992.

- PAGNINI, 2006 : Caterina Pagnini, Costantino de' Servi, architetto-scenografo fiorentino alla corte d'Inghilterra (1611-1615), Florence, 2006.

- Palazzo Pitti, 2003 : Palazzo Pitti : la reggia rivelata, Amelio Fara, Detlef Heikamp éd., (cat. expo., Florence, Palazzo Pitti, 2003-2004), Florence/Milan, 2003.

- PALISSY, (1563) 1996 : Bernard Palissy, Recette véritable, (La Rochelle, 1563), repris dans LESTRINGANT, BARATAUD, 1996. 
- PASQUINI BARISI, 2001 : Isabella Pasquini Barisi, «Tivoli. Villa d'Este », dans CAZZATO, FAGIOLO, GIUSTI, 2001, p. 282-305.

- PERONI, 1992a : Chiara Peroni, «I ninfei ipogei del tardo Manierismo fiorentino », dans NUVOLARI, 1992, p. 154-162.

- PERONI, 1992b : Chiara Peroni, « L'ozio e la frescura : ninfei sotterranei a Firenze tra XVI e XVIII secolo », dans Dalu Jones éd., Il Teatro delle acque, Rome, 1992, p. 90-104.

- PÉROUSE DE MONTCLos, 2000 : Jean-Marie Pérouse de Montclos, Philibert De l'Orme, architecte du roi (1514-1570), Paris, 2000.

- PETRUCCI, 2001 : Francesca Petrucci, « Un nuovo regno d'Arcadia a Firenze », dans PIERI, ZANGHERI, 2001, p. 127-136.

- PETRUZzi, 2001 : Paola Petruzzi, « Capannori, loc. Marlia. Ninfeo di Pan di villa del Vescovo, oggi Pecci-Blunt », dans CAZZATO, FAGIOLO, GIUSTI, 2001, p. 96-98.

- PIEPER, (1991) 1999 : Jan Pieper, « Eine Festung der Sinne : das Château de Maulnes in Burgund », Daidalos, 41, 1991, p. 38-53 ; version française mise à jour sous le titre « Le château de Maulnes en Bourgogne : une première approche du bâtiment, de son programme et de sa signification ", dans Das Château de Maulnes in Burgund. Le Château de Maulnes en Bourgogne, (cat. expo., Aix-la-Chapelle, Lehrstuhl für Baugeschichte und Denkmalpflege, 1999), Aix-la-Chapelle, 1999, p. 8-17.

- PIEPER, 2006a : Jan Pieper éd., Das Château de Maulnes und der Manierismus in Frankreich, (colloque, Aix-la-Chapelle, 2001), (Aachener Bibliothek, 5), Munich/Berlin, 2006.

- PIEPER, 2006b : Jan Pieper, « Das Grottengeschoss in Maulnes », dans PIEPER, 2006a, p. 209-221.

- PIEPER, 2006c : Jan Pieper, Maulnes-en-Tonnerois : ein Konstrukt aus dem Geiste des Manierismus, Stuttgart, 2006.

- PIERELLI, 1991 : Louis D. Pierelli, « La Camera degli Prigioni nella Grotta Grande. Modi e materiali della decorazione », dans ACIDINI LUCHINAT, GARBERO ZORZI, 1991, vol. I, p. 57-66.

- PIERI, ZANGHERI, 2001 : Elisabetta Pieri, Luigi Zangheri éd., Niccolò detto il Tribolo tra arte, architettura e paesaggio, (colloque, Poggio a Caiano, 2000), Poggio a Caiano, 2001.

- PIETROGRANDE, 1999 : Antonella Pietrogrande, « 'Una spelonca di dolci acque amena'. Grotte e ninfeo tra Umanesimo e Manierismo, » dans LAPI BALLERINI, MEDRI, 1999, p. 180-185.

- PIETROGRANDE, 2004 : Antonella Pietrogrande, « La teatralizzazione della natura e dei suoi elementi. Giardino e luogo scenico tra Rinascimento e Barocco » dans BRUNON, MOSSER, RABREAU, 2004, p. 201-212.

- PINELLI, (1993) 1996 : Antonio Pinelli, La belle manière. Anticlassicisme et maniérisme dans l'art du XVI siècle, (Turin, 1993), Paris, 1996.

- PoLIzzI, 1998 : Gilles Polizzi, « Le Poliphile ou l'Idée du jardin : pour une analyse littéraire de l'esthétique colonienne », dans Word \& Image, XIV/1-2, 1998, p. 61-81.

- POULAIN, 1990 : Dominique Poulain, «La grotte », dans Claude d'Urfé et La Bâtie. L'univers d'un gentilhomme de la Renaissance, (cat. expo., Montbrison, Musée d'Allard, 1990), Saint-Étienne, 1990, p. 110-119.

- POZZANA, 1988 : Mariachiara Pozzana, « La struttura e l'esterno », dans Risveglio di un colosso, 1988, p. 110-117. 
- PozzANA, 1990 : Mariachiara Pozzana, «Identità dell'Appennino : la fabbrica, l'acqua, la vegetazione », dans VEZzosI, 1990, p. 108-114.

- POZZANA, 1991 : Mariachiara Pozzana, « La vori in corso a Pratolino », dans Notizie di cantiere, 3, 1991, p. 77-84.

- POZZANA, 1996 : Mariachiara Pozzana, « Il restauro della 'grotticina' nell'Appennino del Giambologna a Pratolino », dans Quasar, 15-16, 1996, p. 118-120.

- PozzANA, 1999 : Mariachiara Pozzana, «L'intervento di conservazione delle grotte : sperimentazione e nuovi materiali nella 'grotticina' dell'Appeninino nel parco di Pratolino », dans LAPI BALLERINI, MEDRI, 1999, p. 290-293.

- PozzANA, 2001 : Mariachiara Pozzana, « Vaglia, loc. Pratolino. 'Grotticina' dentro l'Appennino nel parco della Villa Medicea », dans CAZZATO, FAGIOLO, GIUSTI, 2001, p. 72-73.

- RAGIONIERI, 1981 : Giovanna Ragionieri éd., Il Giardino storico italiano. Problemi di indagine fonti letterarie e storiche, (colloque, Sienne/San Quirico d'Orcia, 1978), Florence, 1981.

- RAVA, 1970 : Carlo Emilio Rava, « Hellbrunn : una Pratolino del nord », dans Antichità viva, IX, 3, 1970, p. 27-45.

- RIETZSCH, 1987 : Barbara Rietzsch, Künstliche Grotten des 16. und 17. Jahrhunderts : Formen der Gestaltung von Außenbau und Innenraum an Beispielen in Italien, Frankreich und Deutschland, Munich, 1987.

- RINALDI, 1979 : Alessandro Rinaldi, « La ricerca della 'terza natura' : artificialia e naturalia nel giardino toscano del '500 », dans FAGIOLO, 1979, p. 154-175.

- RINALDI, 1987a : Alessandro Rinaldi, « Grotte domestiche nell'architettura fiorentina del '600 », dans ACIDINI LUCHINAT, MAGNANI, POZZANA, 1987, p. 31-42.

- RINALDI, 1987b : Alessandro Rinaldi, « Alle radici della residenza barocca. Esempi di grotte domestiche nell'architettura fiorentina tra Sei e Settecento », dans Quaderni di Palazzo Te, 7, 1987, p. 67-80.

- RINALDI, 1991 : Alessandro Rinaldi, « 'Quattro pitaffi sanza le lettere' : i primi anni del Giardino di Boboli e lo ‘spartimento' del Tribolo », dans ACIDINI LUCHINAT, GARBERO ZORZI, 1991, I, p. 19-30.

- RINALDI, 1999 : Alessandro Rinaldi, « Saxum Vivum e non-finito nelle grotte fiorentine del Cinquecento », dans LAPI BALLERINI, MEDRI, 1999, p. 299-307.

- RINALDI, 2001a : Alessandro Rinaldi, « Grotte domestiche di Firenze », dans CAZZATO, FAGIOLO, GIUSTI, 2001, p. 22-26.

- RINALDI, 2001b : Alessandro Rinaldi, «Firenze. Giardino di Boboli, grotta di Madama », dans CAZZATO, FAGIOLO, GIUSTI, 2001, p. 17-18.

- RINALDI, 2001c : Alessandro Rinaldi, « Vaglia, loc. Pratolino. Villa Medicea, grotta di Cupido », dans CAZZATO, FAGIOLO, GIUSTI, 2001, p. 69-71.

- Risveglio di un colosso, 1988 : Risveglio di un colosso. Il restauro dell'Appennino del Giambologna, (cat. expo., Pratolino, villa Demidoff, 1988), Florence, 1988.

- ROSA, 2002 : Marina Rosa, « Lainate. Ninfeo di vila Visconti Borromeo Litta », dans CAZZATO, FAGIOLO, GIUSTI, 2002, p. 172-173. 
- ROSSINI, 2002 : Giorgio Rossini, « Genova. Grotte e parco di villa Pallavicino delle Peschiere », dans CAZZATO, FAGIOLO, GIUSTI, 2002, p. 60-63.

- ROSTAING, 2004 : Aurélia Rostaing, « Francini », dans Allgemeines Künstlerlexikon, XLIII, Munich, 2004, ad vocem.

- ROTUNDO, 1998 : Felicia Rotundo, « Ninfei peruzziani nei giardini del Senese », dans L'acqua nel giardino senese, dans Quaderni dell'Archivio italiano dell'arte dei giardini, 6, 1998, p. 17-30.

- RotUNDO, 2001 : Felicia Rotundo, «Siena. Ninfeo di villa Chigi alle Volte Alte », dans CAzzATO, FAGIOLO, GIUSTI, 2001, p. 142-144.

- Schloss Hellbrunn..., 1997 : Schloss Hellbrunn in Salzburg und seine Grotten : Studien und Beobachtungen zu ihrer Geschichte und Restaurierung, Claudia Maué éd., (cat. expo., Salzbourg, Barockmuseum, 1997), Salzbourg, 1997.

- SETTIS, 1973 : Salvatore Settis, « Esedra e ninfeo nella terminologia architettonica del mondo romano ", dans Hildegarde Temporini éd., Aufstieg und Niedergang der römischen Welt : Geschichte und Kultur Roms im Spiegel der neueren Forschung, I/4, Berlin, 1973, p. 661-745.

- SHEARMAN, (1967) 1990 : John Shearman, Mannerism, (Londres, 1967), Londres, 1990.

- STAGNO, 2002 : Laura Stagno, « Genova. Grotta Doria Galleani (fonte del capitano Lercari) », dans CAZZATO, FAGIOLO, GIUSUTI, 2002, p. 53-56.

- STAGNO, 2005 : Laura Stagno, Palazzo del Principe : Villa di Andrea Doria, Genova, Gênes, 2005.

- STRONG, (1979) 1998 : Roy Strong, The Renaissance Garden in England, (Londres, 1979), Londres, 1998.

- SZAFRANSKA, 1989 : Malgorzata Szafranska, « The philosophy of nature and the grotto in the Renaissance garden », dans Journal of Garden History, IX/2, p. 76-85.

- TEJERO VILLARREAL, 1999 : Beatriz Tejero Villarreal, « La Galleria delle Grotte dei giardini di Filippo II nella ‘Casa Real del Campo’ di Madrid », dans LAPI BALLERINI, MEDRI, 1999, p. 61-68.

- TESTA, 1991 : Fausto Testa, Spazio e allegoria nel giardino manierista. Problemi di estetica, (Pubblicazioni della Facoltà di lettere e filosofia dell'Università di Pavia, 62), Florence, 1991.

- TRABER, 2006 : Suzanne Traber, « Das Bad im Château de Maulnes. Eine Rezeption antiker Thermenanlagen », dans PIEPER, 2006a, p. 175-189.

- Tra Magia, scienza..., 1984 : Tra Magia, scienza e « meraviglia ». Le grotte artificiali dei giardini genovesi nei secoli XVI e XVII, Lauro Magnani éd., (cat. expo., Gênes, Palazzo Bianco, 1984), Gênes, 1984.

- TUTTLE et al., 2002 : Richard Tuttle et al. éd., Jacopo Barozzi da Vignola, Milan, 2002.

- VÉRIN, 2000 : Hélène Vérin, «Salomon de Caus, un mécanicien praticien », dans Revue de l'Art, 129, 2000, p. 70-76.

- VEzzosI, 1985 : Alessandro Vezzosi éd., La Fonte delle fonti. Iconologia degli artifizi d'acqua, (colloque, Florence, Pratolino, 1984), (Pratolino, Laboratorio di Meraviglie, 1), Florence, 1985.

- VEzzosi, 1986 : Alessandro Vezzosi éd., Il Concerto di statue, (Pratolino, Laboratorio di Meraviglie, 4), Florence, 1986.

- VEzzosi, 1990 : Alessandro Vezzosi éd., L’Appennino del Giambologna. Anatomia e identità del Gigante, (colloque, Florence, 1985), (Pratolino, Laboratorio di Meraviglie, 5), Florence, 1990. 
- WILES, (1933) 1975 : Bertha Harnes Wiles, The Fountains of Florentine Sculptors and their followers from Donatello to Bernini, (Cambridge, 1933), New York, 1975.

- WOODBRIDGE, 1986 : Kenneth Woodbridge, Princely Gardens. The origins and development of the French formal style, Londres, 1986.

- ZANGHERI, (1979) 1987 : Luigi Zangheri, Pratolino. Il giardino delle meraviglie, (Florence, 1979), 2 vol., Florence, 1987.

- ZANGHERI, 1985 : Luigi Zangheri, « Salomon de Caus e la fortuna di Pratolino nell’Europa del primo Seicento », dans VEZzosI, 1985, p. 35-43.

- ZANGHERI, 1986 : Luigi Zangheri, « I giardini d'Europa : una mappa della fortuna medicea nel XVI e XVII secolo ", dans Il giardino d'Europa, 1986, p. 82-91.

- ZANGHERI, 1987a : Luigi Zangheri, « Tra abilità e tecnologia : l'acqua nelle grotte del manierismo », dans ACIDINI LUCHINAT, MAGNANI, POZZANA, 1987, p. 9-14.

- ZANGHERI, 1987b : Luigi Zangheri, « La fortuna dei giardini medicei in Europa », dans BAGATTI VALSECCHI, 1987, p. 137-141.

- ZANGHERI, 1991a : Luigi Zangheri, « Vasari e la Grotta Grande », dans ACIDINI LUCHINAT, GARBERO ZORZI, 1991, vol. II, p. 397-402.

- ZANGHERI, 1991b : Luigi Zangheri, « 'Naturalia' et 'curiosa' dans les jardins du XVI siècle », dans MOSSER, TEYSSOT, (1990) 1991, p. 55-63.

- ZANGHERI, 2003 : Luigi Zangheri, Storia del giardino e del paesaggio. Il verde nella cultura occidentale, (Giardini e paesaggio, 6), Florence, 2003.

- ZERNER, 1996 : Henri Zerner, L'art de la Renaissance en France. L'invention du classicisme, Paris, 1996.

\section{NOTES DE FIN}

1. Sur les grottes et nymphées dans l'Antiquité, on rappellera le corpus rassemblé par NEUERBURG, 1965, l'essai de SETTIS, 1973 et la thèse exhaustive de LAVAGNE, 1988. Pour un état plus récent des recherches, voir BRAGANTINI, 1999.

2. On peut citer le témoignage significatif du voyageur écossais Fynes Moryson au sujet de sa visite à Pratolino en 1594 : « I call these by the name of Fountaines, vulgary called Fontana, which are buildings of stone, adorned with many carved Images distilling water, and such are placed in most parts of Italy in the marketplaces, open and uncovered : but in this and like Gardens, these Fountaines are wrought within little houses, which house is vulgary called grotta, that is, Cave (or Den), yet are they not built under the earth but above in the manner of a Cave" (MORYSON, [1617] 1907-1908, vol. I, p. 327-328). En outre, antro, spelonca ou même caverna sont aussi employés au XVI $\mathrm{e}^{\mathrm{e}}$ siècle pour souligner l'idée d'une imitation des cavités naturelles.

3. Dans l'abondante bibliographie commentée qui met en lumière «La postérité du style rustique ", Patricia Falguières propose un très utile recensement des études consacrées aux grottes artificielles maniéristes : voir KRIS, (1926) 2005, p. 279-281.

4. Sur les méthodes de relevé et de représentation graphique, voir ulté-rieurement COGORNO, 2002, avec des exemples d'application sur les grottes génoises.

5. Le comité fut mis en place au début des années 1980 (réorganisé par décret interministériel du 2 août 1986), sous la présidence du philosophe Rosario Assunto, et a été rebaptisé en 2003 Comitato per lo studio e la ricerca sui problemi concernenti i giardini storici. Rappelons que le 
ministère de la Culture français ne s'est doté qu'en 2003 d'une institution comparable, le Conseil national des parcs et jardins.

6. Les fiches ainsi constituées sont partiellement numérisées et consultables dans la base de données Mérimée (http://www.culture.gouv.fr/documentation/memoire/LISTES/merimee/ jardins.htm).

7. De ce point de vue d'ailleurs, un épisode ultérieur à notre cadre chronologique doit être indiqué : la grotte des Capucins, aménagée vers 1623-1624 par Catherine de Gonzague, duchesse de Longueville, dans la crypte de la chapelle Notre-Dame-des-Anges au château de Coulommiers (Seine-et-Marne), présente un décor de coquillages et une iconographie religieuse développées dans des bas-reliefs, des peintures et des statues aujourd'hui mutilés ; elle fut sans doute dédiée à saint François d'Assise et aurait pu servir de retraite spirituelle (LOIZEAU, 2003).

8. Une équipe conduite par Patricia Falguières à l'École des hautes études en sciences sociales a également entrepris l'édition critique de certains des écrits de Salomon de Caus.

9. Signalons qu'un recensement de la bibliographie sur les jardins italiens publiée de 1985 à 2005, coordonné par Lucia Tongiorgi Tommasi et Luigi Zangheri, doit prochainement paraître avec une base de données numérique et des synthèses par secteurs thématiques.

\section{RÉSUMÉS}

Depuis le regain d'intérêt pour les jardins historiques dans les années 1980, les travaux sur les grottes artificielles à la Renaissance n'ont pas connu la même ferveur dans les différents pays. L'Italie, où les grottes sont attestées dès les années 1520, a été abondamment traitée : panoramas régionaux et études monographiques notamment pour la Toscane, le Latium et la Ligurie; fouilles archéologiques et éclairages techniques à l'occasion de chantiers de restauration; contributions plus générales sur des problématiques culturelles. La France a été plus ponctuellement explorée pour les réalisations prestigieuses qui se multiplient dès 1550 ; de nouvelles hypothèses permettent d'esquisser des perspectives de recherche. Les approches touchant au développement des grottes dans le reste de l'Europe, à partir de la seconde moitié du $\mathrm{XVI}^{\mathrm{e}}$ siècle, invitent aujourd'hui à dépasser l'idée traditionnelle d'une diffusion "centrifuge » de l'italianisme et à mieux appréhender le vocabulaire pluriel des grottes qui se met en place à travers l'Europe, en fonction des artistes impliqués et des attentes diverses des commanditaires.

Despite the renewed interest in historical gardens that began during the 1980s, scholarship on artificial grottoes from the Renaissance has not been undertaken everywhere with the same enthusiasm. In Italy, where evidence shows the existence of grottoes dating back to 1520, the field has already been abundantly researched: regional overviews and monographic studies, in particular for Tuscany, Latium and Liguria; archaeological digs and the use of advanced lighting technology during conservation campaigns; and various other contributions to more general cultural issues. France, where spectacular creations abounded from the 1550s on, has been explored much less consistently; new hypotheses have made it possible to evaluate the future direction of scholarship in this field. Recent research on the development of grottos constructed in the rest of Europe, starting in the second half of the sixteenth century, suggests that the traditional idea of a "centrifugal" dissemination of Italianism may need to be questioned and proposes that the varying visual vocabulary used across Europe to describe grottoes can best be understood as a function of the artists employed and the diverse expectations of their patrons.

Seit dem in den achtziger Jahren wieder aufkeimenden Interesse an den historischen Gärten wurden die Arbeiten zu den künstlichen Grotten der Renaissance je nach geografischer Zone mit unterschiedlich großem Eifer behandelt. Italien, wo Grotten ab den 1520-er Jahren bekannt sind, wurde bereits ausführlich in verschiedenen Formen bearbeitet. Davon zeugen regionale 
Panoramen und monografische Studien insbesondere über die Toskana, das Latium und Ligurien; archäologische Ausgrabungen und technische Erörterungen aufgrund von Restaurierungsarbeiten sowie generelle Beiträge zu kulturellen Fragestellungen. Frankreich hingegen wurde eher punktuell in Bezug auf die sich ab 1550 entwickelnden berühmten Bauten untersucht; neue Hypothesen lassen hierbei weiterführende Forschungsrichtungen erkennen. Die Untersuchungen, die sich mit der Entwicklung der Grotten ab der zweiten Hälfte des sechzehnten Jahrhunderts im restlichen Europa befassen, bieten eine Sichtweise, die über die traditionelle Auffassung der strahlenförmigen Verbreitung des Italianismus hinausgeht und das vielseitige Vokabular der Grotten besser handhabt, je nach beteiligten Künstlern und den unterschiedlichen Erwartungen der Auftraggeber.

Dopo l'accrescersi dell'interesse per i giardini storici intorno al 1980, gli studi sulle grotte artificiali del Rinascimento non hanno avuto la stessa intensità nei diversi paesi. L'Italia, dove le grotte sono testimoniate dal 1520, è stata abbondantemente trattata: esistono panorami regionali e studi monografici riguardo la Toscana, il Lazio e la Liguria; scavi archeologici e indagini tecniche eseguite durante cantieri di restauro; contributi più generali sulle problematiche culturali. La Francia è stata studiata più puntualmente riguardo le produzioni di prestigio che si moltiplicarono dal 1550 e nuove ipotesi permettono di abbozzare prospettive di ricerca. Gli approcci che si sono interessati dello sviluppo delle grotte nel resto d'Europa a partire dalla seconda metà del XVI secolo invitano oggi a superare l'idea tradizionalmente accettata di una diffusione "centrifuga" dell'italianismo, e a cercare di comprendere meglio il repertorio molteplice delle grotte diffuso in Europa, in funzione degli artisti implicati e delle diverse aspettative dei committenti.

Desde la renovación de interés por los jardines históricos en los años ochenta, los trabajos sobre las grutas artificiales del Renacimiento no conocieron el mismo entusiasmo en los distintos países. Italia, donde las grutas se certifican a partir de los años 1520, se trató abundantemente: panoramas regionales y estudios monográficos, en particular, para Toscana, el Latium y Liguria; excavaciones arqueológicas y alumbrados técnicos con motivo de obras de restauración; contribuciones más generales sobre problemáticas culturales. Francia se exploró más puntualmente para las realizaciones prestigiosas que se multiplican a partir de 1550; nuevas hipótesis permiten resumir perspectivas de investigación. Los enfoques que afectan al desarrollo de grutas en el resto de Europa, a partir de la segunda mitad del siglo XVI, invitan hoy a superar la idea tradicional de una difusión "centrífuga» del italianismo y a entender mejor el vocabulario plural de las grutas que se establece a través de Europa, en función de los artistas implicados y las distintas expectativas de los comanditarios.

\section{INDEX}

Mots-clés : grottes artificielles, villa, jardin, histoire des jardins, histoire de l'architecture des jardins, historiographie, restauration, typologie, matériaux, iconographie, décor

Index géographique : Italie, France

Keywords : artificial caves, villa, garden, garden history, gardens history, historiography, restoration, typology, materials, iconography, decoration

Index chronologique : 1500, 1600 


\section{AUTEURS}

\section{HERVÉ BRUNON}

Normalien, ancien pensionnaire de la Villa Médicis et boursier de la Villa I Tatti, il est chargé de recherche au CNRS (Centre André Chastel, Paris). Il travaille sur l'histoire culturelle des jardins et des paysages, plus particulièrement en Italie à la Renaissance, ainsi qu'à l'époque actuelle ( $L e$ Jardin contemporain. Renouveau, expériences et enjeux, avec Monique Mosser, 2006). Membre du comité de rédaction des Carnets du paysage, il a dirigé ou co-dirigé plusieurs ouvrages collectifs et vient d'organiser le colloque international Le jardin comme labyrinthe du monde (Louvre, 2007). 